Supporting Information for

\title{
Unlocking Cryptic Metabolites with Mass Spectrometry-Guided Transposon Mutant Selection
}

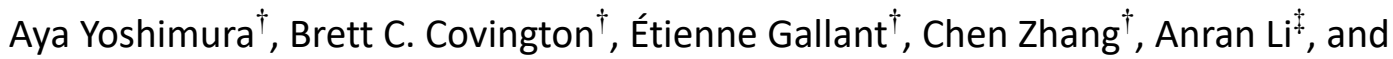 \\ Mohammad R. Seyedsayamdost ${ }^{\dagger, \dagger}, *$
}

'Department of Chemistry, Princeton University, Princeton, NJ 08544, USA

\#Department of Molecular Biology, Princeton University, Princeton, NJ 08544, USA

*Correspondence: mrseyed@princeton.edu 


\section{Materials and Methods}

\section{Bacterial strains}

Burkholderia plantarii ATCC43733 and Burkholderia gladioli ATCC10248 were used throughout. Table S1 lists bacterial strains and Tn mutants used in this study.

\section{Materials and General Procedures}

All chemicals were purchased from Sigma-Aldrich. Bacterial media were purchased from Becton-Dickinson. Q5 DNA polymerase was obtained from New England Biolabs. PCR purification kits was purchased from Qiagen. EZ-Tn5 <KAN-2> Tnp Transposome Kit was purchased from Epicentre.

LB-MOPS, which consists of LB supplemented with $50 \mathrm{mM} \mathrm{MOPS} \mathrm{(pH} \mathrm{7.0),} \mathrm{was} \mathrm{routinely}$ used to culture B. plantarii and B. gladioli. Other media used are: 8-fold diluted LB medium, M63 medium for creation of site-specific mutants, and M9 minimal medium.

High-resolution (HR) HPLC-MS and HR-tandem HPLC-MS were carried out on a 6540 UHD Accurate Mass Q-tof LC-MS system (Agilent), consisting of a 1260 Infinity Series HPLC system, an automated liquid sampler, a diode array detector, a JetStream ESI source, and the 6540 Series Q-tof or on an Agilent UHD Accurate Mass Q-tof UPLC-MS system, equipped with a 1290 Infinity II series UHPLC, an automated liquid sampler, a diode array detector, a JetStream ESI source, and the 6546 series Q-tof. HPLC purifications were carried out on an Agilent 1260 Infinity Series analytical or preparative HPLC system equipped with a photodiode array detector and an automated fraction collector. NMR spectra were collected at the Princeton Chemistry NMR Core Facility in a Bruker Avance III $800 \mathrm{MHz}$ spectrometer equipped with a ${ }^{1} \mathrm{H}$-optimized cryoprobe. Optical density at $600 \mathrm{~nm}$ (OD600) was measured using a Synergy H1 microplate reader (Biotek).

\section{Transposon mutagenesis}

To create random Tn mutants, $B$. plantarii or B. gladioli were plated onto LB-agar plates from frozen stocks, grown overnight at $30^{\circ} \mathrm{C}$, and the resulting colonies used to inoculate $14 \mathrm{~mL}$ bacterial culture tubes containing $5 \mathrm{~mL}$ of LB-MOPS. These were grown overnight, diluted into $20 \mathrm{~mL}$ LB-MOPS in a $125 \mathrm{~mL}$ Erlenmeyer flask to an initial OD600 of 0.05, cultured for $3 \mathrm{~h}$ at $30^{\circ} \mathrm{C} / 250 \mathrm{rpm}$, and pelleted by centrifugation. Cells were washed 3 times with cold $10 \%$ glycerol and resuspended at $70 \mu \mathrm{L} 10 \%$ glycerol. They were then electroporated with $0.5 \mu \mathrm{L}$ of the EZ-Tn5 <KAN-2> Tnp at $1500 \mathrm{~V}$ for $5 \mathrm{~ms}$, returned to ice for $2 \mathrm{~min}$, grown at $30^{\circ} \mathrm{C} / 250 \mathrm{rpm}$ for 2 $\mathrm{h}$, plated on LB plates containing kanamycin $(40 \mu \mathrm{g} / \mathrm{mL})$, and incubated overnight at $30^{\circ} \mathrm{C}$. $^{1}$ The resulting individual colonies were arrayed into 96-well plates containing $110 \mu \mathrm{L}$ LB-MOPS, grown overnight at $30^{\circ} \mathrm{C} / 250 \mathrm{rpm}$, then supplemented with $110 \mu \mathrm{L}$ of $40 \%$ glycerol, and the plates were stored at $-80^{\circ} \mathrm{C}$ until further use.

\section{HPLC-MS-Based SOM Analysis}

Seventy two randomly selected $B$. plantarii Tn mutants from the 96-well storage stocks were streaked out individually onto LB-agar plates containing kanamycin $(40 \mu \mathrm{g} / \mathrm{mL})$. A single colony from each LB plate was used to inoculate $5 \mathrm{~mL}$ of LB-MOPS with kanamycin $(40 \mu \mathrm{g} / \mathrm{mL})$ in a $14 \mathrm{~mL}$ culture tube. After growth at $30^{\circ} \mathrm{C} / 250 \mathrm{rpm}$ for 1 day, the saturated cultures were used to inoculate $20 \mathrm{~mL}$ of LB-MOPS in $125 \mathrm{~mL}$ Erlenmeyer flasks to an initial OD600 of 0.05 . After growth for $24 \mathrm{~h}$ at $30^{\circ} \mathrm{C} / 250 \mathrm{rpm}$, the cells were removed by centrifugation and the supernatant applied directly to a manually-prepared C18 open-column (Phenomenex, $55 \mu \mathrm{m}$, 
$50 \mathrm{mg}$ ), which had been washed with $\mathrm{MeOH}$ and equilibrated in water. After application of the supernatant, the column was washed with $1 \mathrm{~mL}$ each of $0 \%, 50 \%$ and $100 \% \mathrm{MeOH}$ in water. The $50 \% \mathrm{MeOH}$ and $100 \% \mathrm{MeOH}$ fractions were combined and dried in vacuo.

The samples were resuspended in $0.2 \mathrm{~mL}$ of $\mathrm{MeOH}$, and $2 \mu \mathrm{L}$ injected onto a Kinetex column (Phenomenex, $2.6 \mu \mathrm{m}, 10 \times 250 \mathrm{~mm}$ ) on an Agilent 6540 HPLC-MS system. Elution was carried out with water and $\mathrm{MeCN}$ as mobile phases (each containing $0.1 \%$ formic acid) and a gradient of $10 \%-100 \%$ MeCN over 20 minutes at $0.5 \mathrm{~min} / \mathrm{mL}$. HR-MS data were collected in positive ion mode. For each run, $\mathrm{m} / \mathrm{z}$ and retention times were extracted and aligned across all 76 samples (72 Tn mutants, 4 wt replicates) using Agilent Profinder v. B.06.00. The threshold parameters were set to an ion count of $\geq 10^{5}$, yielding 2224 tabulated features (ions with discrete $\mathrm{m} / \mathrm{z}$ and retention time). These were organized into a $25 \times 26$ node grid using a self-organizing map package described previously. ${ }^{2}$ The four wt replicates were averaged and 3-times of this composite subtracted from each of the Tn maps. The colored nodes, therefore, in each difference map contain features that are $>3$-times greater than the corresponding feature in the wt sample. The 72 difference maps thus obtained are shown (Figure S1).

\section{IMS-Based 3D Map Analysis}

For IMS screening, the $B$. gladioli Tn mutant library was used to inoculate ten 96-well plates, with each well containing $110 \mu \mathrm{L}$ LB-MOPS with kanamycin $(40 \mu \mathrm{g} / \mathrm{mL})$. After $24 \mathrm{~h}$ growth at $30^{\circ} \mathrm{C} / 250 \mathrm{rpm}, 2 \mu \mathrm{L}$ of each well were used to inoculate a second set of ten 96 -well plates, with each well containing $110 \mu \mathrm{L}$ of LB-MOPS. The plates were incubated for $24 \mathrm{~h}$ at $30^{\circ} \mathrm{C} / 250 \mathrm{rpm}$. Then, the cells were removed by centrifugation in a 96-well plate centrifuge, and the supernatant subjected to C18-based solid-phase extraction in a 96-well format (Phenomenex, $33 \mu \mathrm{m}, 30 \mathrm{mg} /$ well). After application of the supernatant, the column was washed with $0.5 \mathrm{~mL}$ each of $0 \%, 50 \%$ and $100 \% \mathrm{MeOH}$ in water. The $50 \% \mathrm{MeOH}$ and $100 \% \mathrm{MeOH}$ fractions were combined and dried in vacuo. Each well was resuspended in $20 \mu \mathrm{L}$ of $50 \% \mathrm{MeOH}$ and then imaged using a LAESI DP1000 system (Protea Bioscience) coupled to a LTQ XL mass spectrometer (Thermo). The extension tube connecting the two instruments was kept at $130^{\circ} \mathrm{C}$ with an external heater, and the sample stage was kept at $10^{\circ} \mathrm{C}$ during analysis. The sheath-gas flow was set to $2.0 \mathrm{~L} / \mathrm{h}$. Eighty laser pulses were applied to each well to ablate samples with an $80 \%$ laser energy setting ( $850 \mu \mathrm{J})$ and a $10-\mathrm{Hz}$ frequency. A solution of 2:1 MeCN/water with $0.1 \%$ acetic acid $(\mathrm{v} / \mathrm{v})$ was supplied as the electrospray solution with a syringe pump running at a flow rate of $1 \mu \mathrm{L} / \mathrm{min}^{3}$. The emitter was connected to high-voltage power operating at $+4,000 \mathrm{~V}$ in positive-ion detection mode. All data were visualized in ProteaPlot software.

After data collection, the signals observed in each well were extracted with GMSU-LAESI software (Gubbs), which yielded all $\mathrm{m} / \mathrm{z}$ values and the corresponding intensities per well (i.e., per Tn mutant). The data were binned in 1- $m / z$ units for 3D plotting. Signals with an intensity value lower than a set threshold of 2 -fold the average wt value were not included in the 3D plots. These data were then visualized using the interactive graphing package plotly in R. Peaks from these 3D maps were visually identified and hits were pursued in HPLC-MS analyses from follow-up flask cultures.

\section{Purification and Structure Elucidation of Haereoplantins and Burrioplantin A}

B. plantarii ML939 was streaked out onto an LB-agar plate with kanamycin $(40 \mu \mathrm{g} / \mathrm{mL})$ and grown at $30^{\circ} \mathrm{C}$ overnight. The resulting colonies were used to inoculate $5 \mathrm{~mL}$ of LB-MOPS containing kanamycin $(40 \mu \mathrm{g} / \mathrm{mL})$ in a $14 \mathrm{~mL}$ culture tube. After growth at $30^{\circ} \mathrm{C} / 250 \mathrm{rpm}$ for 24 
$\mathrm{h}$, the overnight was used to inoculate $100 \mathrm{~mL}$ of LB-MOPS plus kanamycin $(40 \mu \mathrm{g} / \mathrm{mL})$ in a 500 $\mathrm{mL}$ Erlenmeyer flask. After growth at $30^{\circ} \mathrm{C} / 250 \mathrm{rpm}$ for $24 \mathrm{~h}$, the $100 \mathrm{~mL}$ culture was used to inoculate $6 \times 4 \mathrm{~L}$ Erlenmeyer flasks, each carrying $1 \mathrm{~L}$ of 8 -fold-diluted LB, to an initial OD600 of 0.05 . After incubation for $48 \mathrm{~h}$ at $30^{\circ} \mathrm{C} / 130 \mathrm{rpm}$, the cells were removed by centrifugation and the supernatant applied directly to a manually-prepared C18 open-column (Phenomenex, 55 $\mu \mathrm{m}, 10 \mathrm{~g})$, which had been washed with $\mathrm{MeOH}$ and equilibrated in water. After application of the supernatant, the column was washed with $80 \mathrm{~mL}$ each of $0 \%, 30 \%, 60 \%$ and $100 \% \mathrm{MeOH}$ in water. Each fraction was dried in vacuo. Haereoplantins and burrioplantin A were detected in the $60 \% \mathrm{MeOH}$ fraction. The $60 \% \mathrm{MeOH}$ fraction was concentrated in vacuo, the residue dissolved in a small volume of $\mathrm{MeOH}$ and fractionated by HPLC using a preparative Luna Phenyl-Hexyl column (Phenomenex, $5 \mu \mathrm{m}, 21.20 \times 250 \mathrm{~mm}$ ) with $\mathrm{H}_{2} \mathrm{O} / \mathrm{MeCN}$ containing $0.1 \%$ formic acid as mobile phases. Material was eluted with a gradient of $20 \% \mathrm{MeCN}$ to $100 \% \mathrm{MeCN}$ over 30 min. Fractions containing haereoplantins and burrioplantin A, as judged by HPLC-MS, were combined and concentrated in vacuo. The residue was then chromatographed on a semi-preparative Luna C18 column (Phenomenex, $5 \mu \mathrm{m}, 10 \times 250 \mathrm{~mm}$ ) with $\mathrm{H}_{2} \mathrm{O} / \mathrm{MeCN}$ containing $0.1 \%$ formic acid as mobile phase. Elution was carried out isocratically at $50 \% \mathrm{MeCN}$, which separated the six compounds and afforded each in $>90 \%$ purity.

The structures of haereoplantin A-E and burrioplantin A were determined by analysis of $1 D$ $\left({ }^{1} \mathrm{H}\right.$ and $\left.{ }^{13} \mathrm{C}\right)$ and 2D (COSY, NOESY, HSQC and HMBC) NMR spectra and HR-MS data. See Table S3 for molecular formulae and HR-MS data. NMR assignments are listed in Tables S4, S6-S10.

Assignment of absolute configuration was conducted using Marfey's protocol with haereoplantin $\mathrm{A}$ and burrioplantin $\mathrm{A} .{ }^{4}$ To a solution of haereoplantin $\mathrm{A}$ or burrioplantin $\mathrm{A}$ (approx. $0.2 \mathrm{mg}$ ) was added $6 \mathrm{~N} \mathrm{HCl}\left(0.2 \mathrm{~mL}\right.$ ), which was reacted for $24 \mathrm{~h}$ at $110{ }^{\circ} \mathrm{C}$. The reaction mixture was dried in vacuo. The obtained hydrolysate was dissolved in $\mathrm{H}_{2} \mathrm{O}(50 \mu \mathrm{L})$, to which 1 $\mathrm{M} \mathrm{NaHCO}_{3}(20 \mu \mathrm{L})$ and L- or D-FDAA $(1 \% \mathrm{w} / \mathrm{v}$ in acetone, $100 \mu \mathrm{L})$ were added, and the mixture was stirred for $1 \mathrm{~h}$ at room temperature. The solution was neutralized with $1 \mathrm{~N} \mathrm{HCl}(20 \mu \mathrm{L})$, evaporated, and then dissolved in $\mathrm{MeOH}$. The derivatives were analyzed by HPLC-Qtof-MS. HPLC separation was performed on a Kinetex column (Phenomenex, $2.6 \mu \mathrm{m}, 10 \times 250 \mathrm{~mm}$ ) with a gradient elution of $10 \% \mathrm{MeCN}$ to $100 \% \mathrm{MeCN}$ over $45 \mathrm{~min}$ (both water and MeCN contained $0.1 \%$ formic acid. The result of Marfey's analysis are shown in Table S5.

\section{Purification and Structural Elucidation of Gladiobactin A}

B. plantarii ML940 was streaked out onto an LB-agar plate with kanamycin $(40 \mu \mathrm{g} / \mathrm{mL})$ and grown at $30^{\circ} \mathrm{C}$ overnight. The resulting colonies were used to inoculate $5 \mathrm{~mL}$ of LB-MOPS plus kanamycin $(40 \mu \mathrm{g} / \mathrm{mL})$ in a $14 \mathrm{~mL}$ culture tube. After growth at $30^{\circ} \mathrm{C} / 250 \mathrm{rpm}$ for $24 \mathrm{~h}$, the overnight was used to inoculate $100 \mathrm{~mL}$ of LB-MOPS + kanamycin $(40 \mu \mathrm{g} / \mathrm{mL}$ ) in a $500 \mathrm{~mL}$ Erlenmeyer flask. After growth at $30^{\circ} \mathrm{C} / 250 \mathrm{rpm}$ for $24 \mathrm{~h}$, the $100 \mathrm{~mL}$ culture was used to inoculate $6 \times 2$ L Erlenmeyer flasks, each carrying $1 \mathrm{~L}$ of M9 minimal medium with glycerol $(0.2 \%$ $\mathrm{v} / \mathrm{v}$ ) as the carbon source. After growth $48 \mathrm{~h}$ at $30^{\circ} \mathrm{C} / 120 \mathrm{rpm}$, the cells spun down and the supernatant applied directly to a manually-prepared C18 open-column (Phenomenex, $55 \mu \mathrm{m}$, $10 \mathrm{~g})$. The column was washed with $80 \mathrm{~mL}$ each of $0 \%, 30 \%, 60 \%$ and $100 \% \mathrm{MeOH}$ in water. Each fraction was dried in vacuo. Gladiobactin A was detected in the $60 \%$ and $100 \% \mathrm{MeOH}$ fractions. These were combined, concentrated in vacuo, the residue dissolved in a small volume of $\mathrm{MeOH}$, and fractionated by HPLC on a preparative Luna C18 column (Phenomenex, $5 \mu \mathrm{m}$, $21.20 \times 250 \mathrm{~mm}$ ) with $\mathrm{H}_{2} \mathrm{O} / \mathrm{MeCN}$ plus $0.1 \%$ formic acid as mobile phase. Elution was carried out from $20 \%$ MeCN to $100 \%$ MeCN over 30 min. Fractions containing gladiobactin A, as judged 
by HPLC-MS, were combined, concentrated in vacuo, dissolved in $\mathrm{MeOH}$, and chromatographed on a semi-preparative Luna C18 column (Phenomenex, $5 \mu \mathrm{m}, 10 \times 250 \mathrm{~mm}$ ) with $\mathrm{H}_{2} \mathrm{O} / \mathrm{MeCN}$ plus $0.1 \%$ formic acid as mobile phase. Elution was carried out isocratically with $50 \% \mathrm{MeCN}$ and yielded pure gladiobactin $A$. The structure of gladiobactin A was determined by analysis of ${ }^{1} \mathrm{H}$, COSY, TOCSY, HSQC and HMBC spectra and HR-MS data (see Tables S3, S13). Absolute configurations were determined using Marfey's method and the appropriate standards as described above for haereoplantin A (Table S5).

\section{Creation of Site-Specific Deletion Mutants in B. plantarii}

All deletion mutants were constructed by natural competence transformation with linear DNA fragments, which were created by joining three fragments corresponding to the upstream and downstream $1 \mathrm{~kb}$ regions flanking the gene to be deleted and the tetracycline resistance marker (tet). Competent $B$. plantarii cells were generated by growing the bacteria overnight in a $5 \mathrm{~mL}$ low-salt LB-medium at $37^{\circ} \mathrm{C} / 200 \mathrm{rpm}$. The overnight culture was used to inoculate $3 \mathrm{~mL}$ of M63 medium in a $50 \mathrm{~mL}$ Erlenmeyer flask grown at $37^{\circ} \mathrm{C} / 200 \mathrm{rpm}$. After $27 \mathrm{~h}$, the cells were pelleted by centrifugation at $16,000 \mathrm{~g}$ for $3 \mathrm{~min}$, and the supernatant was discarded. The cells were resuspended in $50 \mu \mathrm{L}$ of M63 medium in a sterile $1.5 \mathrm{~mL}$ Eppendorf tube. $~ 500 \mathrm{ng}$ of linear DNA fragment was mixed with the cells by gently tapping the tube, and the resulting mixture was incubated at room temperature for $30 \mathrm{~min}$. The mixture was then transferred into $2-3 \mathrm{~mL}$ of M63 medium in a $14 \mathrm{~mL}$ culture tube and grown at $37^{\circ} \mathrm{C} / 200 \mathrm{rpm}$ overnight. The overnight culture was pelleted by centrifugation and the cells were resuspended in $50 \mu \mathrm{L}$ M63 medium and plated on LB agar supplemented tetracycline $(20 \mu \mathrm{g} / \mathrm{mL})$. The plate was then incubated at $37^{\circ} \mathrm{C}$ for $24 \mathrm{~h}$ or until colonies developed. The mutant colonies were verified by PCR and sequencing. Primers used in this study are listed in Table S1.

\section{Identification of Tn5 Insertion Sites}

The desired mutant was cultured in $5 \mathrm{~mL}$ of LB-MOPS overnight, as described above, and then pelleted by centrifugation. Genomic DNA was isolated using the Promega Wizard Genomic DNA Purification Kit. Arbitrary PCR was then carried as previously reported without modifications ${ }^{5}$ to amplify the Tn5-adjacent regions, which were sequenced at Genewiz. The insertion sites were identified using the publically available genome sequence of $B$. plantarii.

\section{Spermidine Supplementation Experiments}

A $5 \mathrm{~mL}$ overnight culture of $B$. gladioli was prepared in LB-MOPS in a $14 \mathrm{~mL}$ culture tube, as described above, and incubated at $30^{\circ} / 250 \mathrm{rpm}$. The overnight culture was diluted into 20 $\mathrm{mL}$ of $\mathrm{M} 9$ medium plus glycerol $(0.2 \% \mathrm{v} / \mathrm{v})$ and supplemented with increasing concentrations of spermidine $(0-3.2 \mathrm{mM})$ in a $125 \mathrm{~mL}$ Erlenmeyer flask. The cultures were grown at $30^{\circ} \mathrm{C} / 200$ rpm for 48 hours and OD600 was subsequently measured. Supernatants from the cultures were filtered and analyzed on an Agilent UHD Accurate Mass UPLC-MS system with the 6454 series Q-tof. The samples were resolved on an Agilent Poroshell $120 \mathrm{EC}-\mathrm{C} 18$ column (1.9 $\mu \mathrm{m}$, $2.1 \times 50 \mathrm{~mm}$ ) at $0.5 \mathrm{~mL} / \mathrm{min}$ using $\mathrm{H}_{2} \mathrm{O} / \mathrm{MeCN}$ (+0.1\% formic acid) as mobile phase. Elution was carried out isocratically for $1.5 \mathrm{~min}$ at $20 \% \mathrm{MeCN}$, followed by a gradient from $15-100 \%$ MeCN over $3.5 \mathrm{~min}$. The extracted ion chromatogram for gladiobactin $A$ and ferricgladiobactin $\mathrm{A}\left([\mathrm{M}+\mathrm{H}]^{+}=1105.5848\right.$ and $[\mathrm{M}-2 \mathrm{H}+\mathrm{Fe}]^{+}=1158.4967$, respectively) was integrated and normalized by OD600. Results from two independent biological replicates were averaged to give the values in Fig. $6 \mathrm{C}$. 


\section{SI Tables}

Table S1. Strains (top) and primers (bottom) used in this study.

\begin{tabular}{|c|c|c|}
\hline Bacterial strain & Description & Source \\
\hline B. plantarii ATCC 43733 & wild-type & ATCC \\
\hline B. gladioli ATCC 10248 & wild-type & ATCC \\
\hline B. plantarii ML939 & helicase::Tn5 & This study \\
\hline B. plantarii ML943 & helicase::tet & This study \\
\hline B. plantarii ML946 & helicase::Tn5, hptC::tet & This study \\
\hline B. plantarii ML944 & helicase::Tn5, bptE::tet & This study \\
\hline B. gladioli ML940 & potF::Tn5 & This study \\
\hline
\end{tabular}

\begin{tabular}{|c|c|c|}
\hline Primer name & Primer Sequence & Purpose \\
\hline NRPS_F1 & GATCGTCAACGGCGAGAGAGCTACG & \multirow{6}{*}{$\begin{array}{l}\text { Construction of } \\
\text { B. plantarii ML946 }\end{array}$} \\
\hline NRPS_R1 & AGGAGGTTCCGACGGGCCAAGGCACTGCG & \\
\hline NRPS_Ftet & GCCCGTCGGAACCTCCTTTAACTCCTCAAAACGAAC & \\
\hline NRPS_Rtet & TAGCCGTCGGGAGTGGTGAATCCGTTAGCGAGG & \\
\hline NRPS_F2 & GATTCACCACTCCCGACGGCTATCTGGCGCGG & \\
\hline NRPS_R2 & CCGGCTTGTGCGAAATCGAGTCC & \\
\hline helicase_F1 & GCGATGAGGGCGACCGAGCA & \multirow{6}{*}{$\begin{array}{l}\text { Construction of } \\
\text { B. plantarii ML943 }\end{array}$} \\
\hline helicase_R1 & GGAGGTTCCCGGTGGGTGAAACGTCGGCG & \\
\hline helicase_Ftet & CACCCACCGGGAACCTCCTTTAACTCCTCAAAACGAAC & \\
\hline helicase_Rtet & AATGTCGGCGGTGGTGAATCCGTTAGCGAGGTGCC & \\
\hline helicase_F2 & GGATTCACCACCGCCGACATTTCACGATGCG & \\
\hline helicase_R2 & GCACCTTGCCGCCATGTGG & \\
\hline Big_NRPS_F1 & CAGGTTGCCCGCCCCATCG & \multirow{6}{*}{$\begin{array}{c}\text { Construction of } \\
\text { B. plantarii ML944 }\end{array}$} \\
\hline Big_NRPS_R1 & TTAAAGGAGGTTCCGCGCTCTCTCAATTCGCAATTCCATG & \\
\hline Big_NRPS_Ftet & GAGAGAGCGCGGAACCTCCTTTAACTCCTCAAAACGAA & \\
\hline Big_NRPS_Rtet & GCATGCACATTGGAGTGGTGAATCCGTTAGCAGG & \\
\hline Big_NRPS_F2 & ATTCACCACTCCAATGTGCATGCGGCTGTAACCGTTTC & \\
\hline Big_NRPS_R2 & TCGCCCACCCAGCCTGACTC & \\
\hline
\end{tabular}


Table S2. AntiSMASH results of the $B$. plantarii genome.

\begin{tabular}{|c|c|c|c|}
\hline Cluster & Type & Most similar known cluster & Similarity \\
\hline 1 & NRPS-T1PKS & oxalomycin & $9 \%$ \\
\hline 2 & NRPS-T1PKS & glidobactin & $15 \%$ \\
\hline 3 & betalactone-terpene & barbamide & $33 \%$ \\
\hline 4 & $\begin{array}{c}\text { NRPS-homoserine } \\
\text { lactone }\end{array}$ & bactobolin & $9 \%$ \\
\hline 5 & siderophore & staphylobactin & $18 \%$ \\
\hline 6 & homoserine lactone & & \\
\hline 7 & phosphonate & phosphinothricintripeptide & $6 \%$ \\
\hline 8 & bacteriocin & & \\
\hline 9 & NRPS-betalactone & fragin & $62 \%$ \\
\hline 10 & NRPS & gramibactin & $40 \%$ \\
\hline 11 & NRPS & rhizomide & $100 \%$ \\
\hline 12 & betalactam & & \\
\hline 13 & terpene & & \\
\hline 14 & terpene & & \\
\hline 15 & bacteriocin & & \\
\hline 16 & T1PKS & capsular polysaccharide & $25 \%$ \\
\hline 17 & homoserine lactone & & \\
\hline 18 & NRPS & Iysobactin & $3 \%$ \\
\hline 19 & T2PKS & APE Vf & $30 \%$ \\
\hline 20 & bacteriocin & & \\
\hline 21 & NRPS-T1PKS & & \\
\hline 22 & NRPS & pyochelin & $60 \%$ \\
\hline 23 & CDPS & bicyclomycin & $75 \%$ \\
\hline 24 & terpene & & \\
\hline 25 & NRPS & & \\
\hline
\end{tabular}


Table S3. AntiSMASH results of the $B$. gladioli genome.

\begin{tabular}{|c|c|c|c|}
\hline Cluster & Type & Most similar known cluster & Similarity \\
\hline 1 & homoserine lactone & & \\
\hline 2 & T1PKS & lipopolysaccharide & $5 \%$ \\
\hline 3 & NRPS & sulfazecin & $100 \%$ \\
\hline 4 & NRPS & & \\
\hline 5 & T1PKS-NRPS & orfamide & $30 \%$ \\
\hline 6 & terpene & lasalocid & $7 \%$ \\
\hline 7 & transAT-PKS & etnangien & $68 \%$ \\
\hline 8 & NRPS & rhizomide & $100 \%$ \\
\hline 9 & phosphonate & phosphinothricintripeptide & $6 \%$ \\
\hline 10 & bacteriocin & & \\
\hline 11 & NRPS & pyoverdine & $1 \%$ \\
\hline 12 & NRPS & gramibactin & $46 \%$ \\
\hline 13 & NRPS & rhizomide & $100 \%$ \\
\hline 14 & T1PKS & lactimidomycin & $66 \%$ \\
\hline 15 & terpene & & \\
\hline 16 & terpene & & \\
\hline 17 & terpene & desotamide & $9 \%$ \\
\hline 18 & NRPS & icosalide & $100 \%$ \\
\hline 19 & betalactone-terpene & barbamide & $41 \%$ \\
\hline
\end{tabular}


Table S4. Features observed in the four regions of interest upon HPLC-MS-based SOM analysis of $B$. plantarii Tn mutants. The locations of the four regions are shown in the map to the bottom left. The features in each region of interest (ROI) are tabulated. The feature ID is comprised of " $\mathrm{M}$ " followed by the $\mathrm{m} / \mathrm{z}$ of the compound and " $\mathrm{T}$ " followed by the feature retention time, both of which are determined by the MassHunter Profinder feature extraction algorithm.

\section{ROI 1}

\begin{tabular}{|cc|}
\hline Feature ID & Fold \\
& Change \\
\hline M301.2T9.8 & 6 \\
M414.2T2.9 & $>100$ \\
M470.2T5.1 & $>100$ \\
M472.2T5.4 & $>100$ \\
M477.2T4.4 & $>100$ \\
M497.2T3.8 & 15 \\
M528.2T3.1 & $>100$ \\
M542.2T3.2 & 7 \\
M560.2T5.7 & $>100$ \\
M578.2T5 & $>100$ \\
M649.3T5.7 & $>100$ \\
M764.3T3.4 & 58 \\
M1103.7T8.3 & $>100$ \\
\hline
\end{tabular}

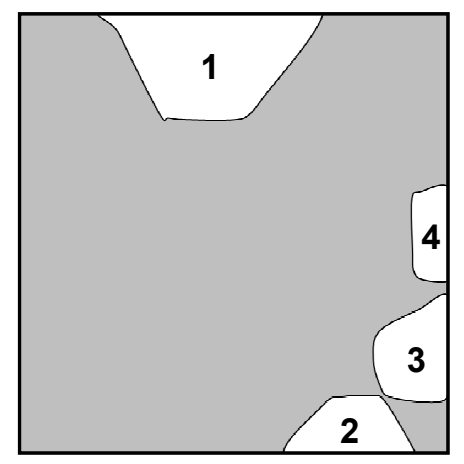

\section{ROI 2}

\begin{tabular}{|cc|}
\hline Feature ID & $\begin{array}{c}\text { Fold } \\
\text { Change }\end{array}$ \\
\hline M603.3T4.8 & $>100$ \\
\hline
\end{tabular}

\section{ROI 3}

\begin{tabular}{|cc|}
\hline Feature ID & $\begin{array}{c}\text { Fold } \\
\text { Change }\end{array}$ \\
\hline M284.1T12.4 & 10 \\
M385.2T4.7 & 8 \\
M402.2T2.9 & 53 \\
M411.2T3.1 & 10 \\
M508.2T4.4 & 9 \\
M545.2T2.7 & 7 \\
M627.3T6 & 14 \\
M635.3T2.8 & 14 \\
M821.4T9.1 & 2 \\
M1014.5T3 & 6 \\
\hline
\end{tabular}

\section{ROI 4}

\begin{tabular}{|cc|}
\hline Feature ID & $\begin{array}{c}\text { Fold } \\
\text { Change }\end{array}$ \\
\hline M219.1T10.9 & 5 \\
M242.1T2.5 & 5 \\
M628.3T2.7 & 6 \\
M809.4T10.2 & 4 \\
M1021.5T9.6 & 5 \\
M1105.5T9.9 & 3 \\
\hline
\end{tabular}


Table S5. Observed and calculated $\mathrm{m} / \mathrm{z}$ and molecular formulae for metabolites identified in this work.

\begin{tabular}{c|cccc} 
Compound & {$\left[\mathrm{M}+\mathrm{H}^{+}\right]_{\text {calc }}$} & {$[\mathrm{M}+\mathrm{H}]^{+}{ }_{\text {obs }}$} & $\Delta$ ppm & Molecular formula \\
\hline Haereoplantin A & 809.4080 & 809.4068 & 1.5 & $\mathrm{C}_{41} \mathrm{H}_{56} \mathrm{~N}_{6} \mathrm{O}_{11}$ \\
Haereoplantin B & 837.4393 & 837.4360 & 3.9 & $\mathrm{C}_{43} \mathrm{H}_{60} \mathrm{~N}_{6} \mathrm{O}_{11}$ \\
Haereoplantin C & 793.4131 & 793.4112 & 2.4 & $\mathrm{C}_{41} \mathrm{H}_{56} \mathrm{~N}_{6} \mathrm{O}_{10}$ \\
Haereoplantin D & 773.4444 & 773.4423 & 2.7 & $\mathrm{C}_{39} \mathrm{H}_{60} \mathrm{~N}_{6} \mathrm{O}_{10}$ \\
Haereoplantin E & 708.3603 & 708.3590 & 1.8 & $\mathrm{C}_{37} \mathrm{H}_{49} \mathrm{~N}_{5} \mathrm{O}_{9}$ \\
Burrioplantin A & 1021.5241 & 1021.5221 & 2.0 & $\mathrm{C}_{51} \mathrm{H}_{72} \mathrm{~N}_{8} \mathrm{O}_{14}$ \\
Gladiobactin A & 1105.5848 & 1105.5857 & 0.8 & $\mathrm{C}_{45} \mathrm{H}_{80} \mathrm{~N}_{14} \mathrm{O}_{18}$ \\
Icosalide A & 713.4695 & 713.4689 & 0.8 & $\mathrm{C}_{36} \mathrm{H}_{64} \mathrm{~N}_{4} \mathrm{O}_{10}$ \\
Icosalide B & 685.4382 & 685.4370 & 1.8 & $\mathrm{C}_{34} \mathrm{H}_{60} \mathrm{~N}_{4} \mathrm{O}_{10}$ \\
Gladiolin & 779.5304 & 779.5296 & 1.0 & $\mathrm{C}_{44} \mathrm{H}_{74} \mathrm{O}_{11}$
\end{tabular}


Table S6. NMR assignments for haereoplantin A in DMSO-d6 from $N$ - to $C$-terminus. The structure and numbering scheme for haereoplantin A are shown above the table.

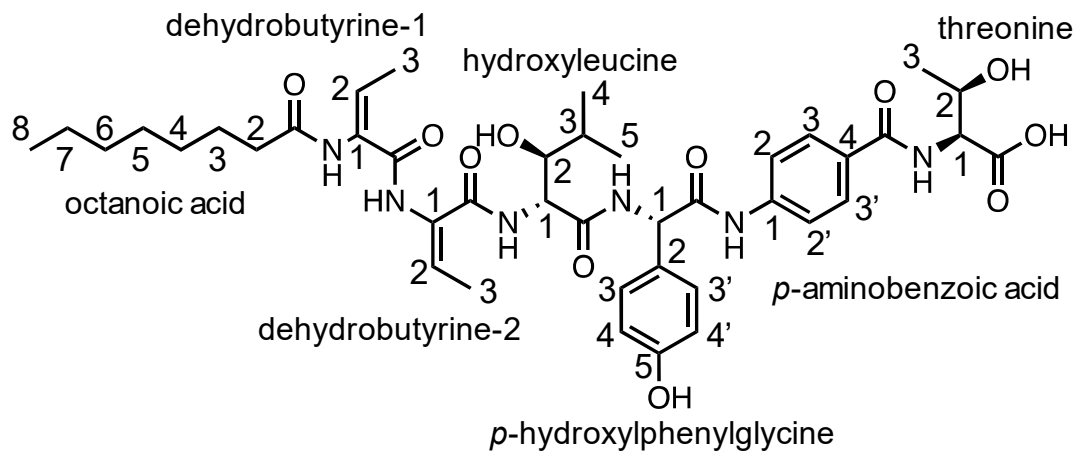

\begin{tabular}{|c|c|c|c|}
\hline Residue & Position & ${ }^{13} \mathrm{C}$ & ${ }^{1} \mathrm{H}$ (mult., $J$ in $\mathrm{Hz}$ ) \\
\hline \multirow[t]{4}{*}{ octanoic acid } & $C=0$ & 172.7 & \\
\hline & 2 & 34.8 & $2.18(\mathrm{~m})$ \\
\hline & $3-7$ & $21.7-31.6$ & $1.10-1.54$ \\
\hline & 8 & 13.7 & 0.81 \\
\hline \multirow[t]{5}{*}{ dehydrobutyrine-1 } & $C=0$ & 163.9 & \\
\hline & 1 & 131.3 & \\
\hline & 2 & 118.7 & $5.57(q, 7.0)$ \\
\hline & 3 & 12.5 & $1.72(d, 7.1)$ \\
\hline & $\mathrm{NH}$ & & $10.01(s)$ \\
\hline \multirow[t]{5}{*}{ dehydrobutyrine-2 } & $C=0$ & 163.8 & \\
\hline & 1 & 129.2 & \\
\hline & 2 & 127.5 & $5.79(q, 7.1)$ \\
\hline & 3 & 13.1 & $1.92(d, 7.1)$ \\
\hline & $\mathrm{NH}$ & & $9.78(\mathrm{~s})$ \\
\hline \multirow[t]{8}{*}{ hydroxyleucine } & $C=0$ & 170.5 & \\
\hline & 1 & 55.7 & $4.50(\mathrm{dd}, 3.0,9.0)$ \\
\hline & 2 & 76.3 & $3.58(\mathrm{~m})$ \\
\hline & 3 & 30.1 & $1.63(\mathrm{~m})$ \\
\hline & 4 & 18.7 & 0.91 \\
\hline & 5 & 18.9 & 0.79 \\
\hline & $\mathrm{OH}$ & & $4.75(d, 8.1)$ \\
\hline & $\mathrm{NH}$ & & $7.85(d, 8.7)$ \\
\hline
\end{tabular}




\begin{tabular}{|c|c|c|c|}
\hline \multirow[t]{7}{*}{$p$-hydroxylphenylglycine } & $\mathrm{C}=\mathrm{O}$ & 169.3 & \\
\hline & 1 & 56.8 & $5.48(d, 7.5)$ \\
\hline & 2 & 127.7 & \\
\hline & $3,3^{\prime}$ & 128.6 & $7.26(d, 8.6)$ \\
\hline & $4,4^{\prime}$ & 114.9 & $6.68(d, 8.6)$ \\
\hline & 5 & 157.1 & \\
\hline & $\mathrm{NH}$ & & $8.25(d, 7.6)$ \\
\hline \multirow[t]{6}{*}{$p$-aminobenzoic acid } & $\mathrm{C}=\mathrm{O}$ & 164.4 & \\
\hline & 1 & 141.2 & \\
\hline & $2,2^{\prime}$ & 118.4 & $7.72(d, 8.6)$ \\
\hline & $3,3^{\prime}$ & 127.3 & $7.64(d, 8.6)$ \\
\hline & 4 & 129.4 & \\
\hline & $\mathrm{NH}$ & & 10.15 (s) \\
\hline \multirow[t]{5}{*}{ threonine } & $C=O$ & 171.9 & \\
\hline & 1 & 56.9 & $3.94(\mathrm{~m})$ \\
\hline & 2 & 65.5 & $3.96(\mathrm{~m})$ \\
\hline & 3 & 18.7 & 0.91 \\
\hline & $\mathrm{NH}$ & & $7.62(d, 5.8)$ \\
\hline
\end{tabular}


Table S7. Marfey's analysis of haereoplantin A, burrioplantin A and gladiobactin A.

\begin{tabular}{|c|c|c|c|c|}
\hline \multirow{2}{*}{ Haereoplantin A } & \multicolumn{2}{|c|}{ Rt, hydrolyzed haereoplantin A } & $\begin{array}{c}\text { Rt, standard } \\
\text { L-amino acid }\end{array}$ & $\begin{array}{c}\text { Stereo- } \\
\text { chemistry }\end{array}$ \\
\hline & L-FDAA & D-FDAA & L-FDAA & \\
\hline$(2 R, 3 S)$-hydroxyleucine & 35.2 & 30.3 & $35.2^{a}$ & $2 R, 3 S$ \\
\hline$p$-hydroxylphenylglycine & 40.9 & 41.7 & 40.9 & $\mathrm{~L}$ \\
\hline threonine & 23.1 & 26.6 & 23.1 & $\mathrm{~L}$ \\
\hline
\end{tabular}

${ }^{a}(2 \mathrm{R}, 3 \mathrm{~S})$-hydroxyleucine was used as standard

\begin{tabular}{|c|c|c|c|c|}
\hline \multirow{2}{*}{ Burrioplantin A } & \multicolumn{2}{|c|}{ Rt, hydrolyzed burrioplantin A } & $\begin{array}{c}\text { Rt, standard } \\
\text { L-amino acid }\end{array}$ & $\begin{array}{c}\text { Stereo- } \\
\text { chemistry }\end{array}$ \\
\hline serine & 22.5 & 22.1 & 22.1 & $\mathrm{D}$ \\
\hline alanine & 27.2 & 30.1 & 27.2 & $\mathrm{~L}$ \\
\hline$p$-hydroxylphenylglycine & 41.4 & 40.9 & 40.9 & $\mathrm{D}$ \\
\hline phenylalanine & 37.9 & 40.2 & 37.9 & $\mathrm{~L}$ \\
\hline homoserine & 23.1 & 26.6 & 23.1 & $\mathrm{~L}$ \\
\hline proline & $28.2 / 29.4$ & $28.2 / 29.4$ & 28.2 & $\mathrm{D}+\mathrm{L}$ \\
\hline
\end{tabular}

\begin{tabular}{|c|c|c|c|c|}
\hline Gladiobactin A & \multicolumn{2}{|c|}{ Rt, hydrolyzed gladiobactin A } & $\begin{array}{c}\text { Rt, standard } \\
\text { L-amino acid }\end{array}$ & $\begin{array}{c}\text { Stereo- } \\
\text { chemistry }\end{array}$ \\
\hline & L-FDAA & D-FDAA & L-FDAA & L \\
\hline Iysine & 38.7 & 39.7 & 38.7 & L \\
\hline ornithine & 36.8 & 34.8 & - & L-erythro \\
\hline 3-hydroxyaspartic acid & 22.7 & 21.6 & - & D+L \\
\hline serine & $22.1 / 22.5$ & $22.1 / 22.5$ & - & D \\
\hline 5-hydroxynorvaline & 25.5 & 24.6 & - & $\mathrm{D}$ \\
\hline proline & 29.3 & 28.1 & 28.1 & - \\
\hline
\end{tabular}


Table S8. NMR assignments for haereoplantin B in DMSO-d6 from $N$ - to $C$-terminus. The structure and numbering scheme for haereoplantin B are shown above the table.

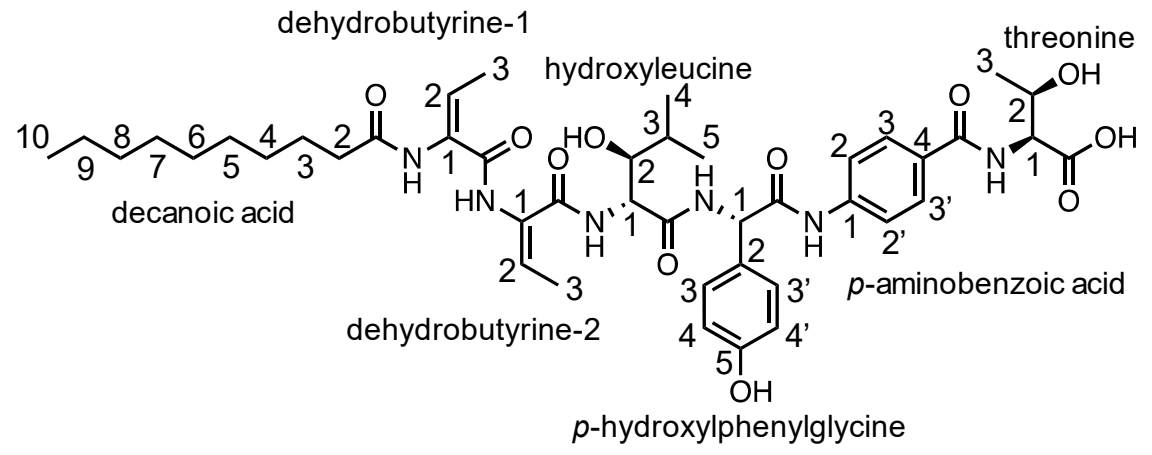

\begin{tabular}{|c|c|c|c|}
\hline Residue & Position & ${ }^{13} \mathrm{C}$ & ${ }^{1} \mathrm{H}$ (mult., $J$ in $\mathrm{Hz}$ ) \\
\hline \multirow[t]{4}{*}{ decanoic acid } & $C=O$ & ND & \\
\hline & 2 & ND & $2.18(\mathrm{~m})$ \\
\hline & $3-9$ & ND & $1.14-1.54$ \\
\hline & 10 & ND & 0.79 \\
\hline \multirow[t]{5}{*}{ dehydrobutyrine-1 } & $C=O$ & ND & \\
\hline & 1 & ND & \\
\hline & 2 & ND & $5.57(q, 7.9)$ \\
\hline & 3 & 12.2 & $1.72(d, 7.2)$ \\
\hline & $\mathrm{NH}$ & & $10.03(\mathrm{~s})$ \\
\hline \multirow[t]{5}{*}{ dehydrobutyrine-2 } & $C=O$ & ND & \\
\hline & 1 & ND & \\
\hline & 2 & ND & $5.78(q, 7.4)$ \\
\hline & 3 & 13.0 & $1.92(d, 7.6)$ \\
\hline & $\mathrm{NH}$ & & $9.79(\mathrm{~s})$ \\
\hline \multirow[t]{8}{*}{ hydroxyleucine } & $C=O$ & ND & \\
\hline & 1 & ND & $4.50(d d, 3.3,8.6)$ \\
\hline & 2 & ND & $3.57(\mathrm{~m})$ \\
\hline & 3 & ND & $1.62(\mathrm{~m})$ \\
\hline & 4 & 18.6 & 0.91 \\
\hline & 5 & 18.7 & 0.76 \\
\hline & $\mathrm{OH}$ & & $4.76(d, 9.2)$ \\
\hline & $\mathrm{NH}$ & & $7.86(d, 9.0)$ \\
\hline
\end{tabular}




\begin{tabular}{|c|c|c|c|}
\hline \multirow[t]{7}{*}{$p$-hydroxylphenylglycine } & $\mathrm{C}=\mathrm{O}$ & ND & \\
\hline & 1 & ND & $5.47(d, 7.4)$ \\
\hline & 2 & ND & \\
\hline & $3,3^{\prime}$ & 128.4 & $7.25(d, 8.4)$ \\
\hline & $4,4^{\prime}$ & 114. & $6.68(d, 8.3)$ \\
\hline & 5 & ND & \\
\hline & $\mathrm{NH}$ & & $8.23(d, 7.8)$ \\
\hline \multirow[t]{6}{*}{$p$-aminobenzoic acid } & $\mathrm{C}=\mathrm{O}$ & ND & \\
\hline & 1 & ND & \\
\hline & $2,2^{\prime}$ & 127.1 & $7.71(d, 9.2)$ \\
\hline & $3,3^{\prime}$ & 118.4 & $7.64(d, 9.1)$ \\
\hline & 4 & ND & \\
\hline & $\mathrm{NH}$ & & 10.15 (s) \\
\hline \multirow[t]{5}{*}{ threonine } & $C=0$ & ND & \\
\hline & 1 & ND & $3.94(\mathrm{~m})$ \\
\hline & 2 & ND & $3.94(\mathrm{~m})$ \\
\hline & 3 & ND & 0.91 \\
\hline & $\mathrm{NH}$ & & $7.61(d, 5.1)$ \\
\hline
\end{tabular}


Table S9. NMR assignments for haereoplantin $\mathrm{C}$ in DMSO-d6 from $\mathrm{N}$ - to $\mathrm{C}$-terminus. The structure and numbering scheme for haereoplantin $\mathrm{C}$ are shown above the table.

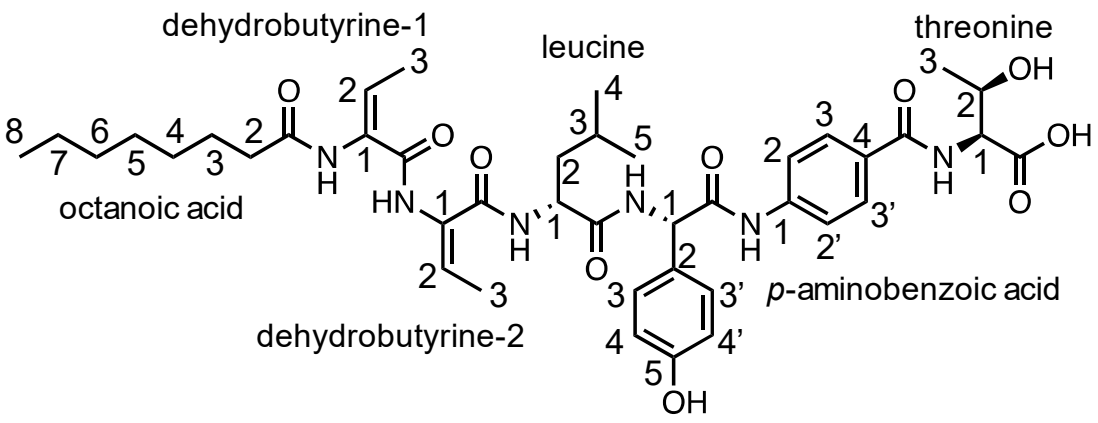

p-hydroxylphenylglycine

\begin{tabular}{|c|c|c|c|}
\hline Residue & Position & ${ }^{13} \mathrm{C}$ & ${ }^{1} \mathrm{H}$ (mult., $J$ in $\mathrm{Hz}$ ) \\
\hline \multirow[t]{4}{*}{ octanoic acid } & $C=0$ & ND & \\
\hline & 2 & 34.4 & $2.19(\mathrm{~m})$ \\
\hline & $3-7$ & $21.6-32.2$ & $1.11-1.57$ \\
\hline & 8 & 13.4 & 0.80 \\
\hline \multirow[t]{5}{*}{ dehydrobutyrine-1 } & $C=0$ & ND & \\
\hline & 1 & ND & \\
\hline & 2 & 117.7 & $5.51(q, 7.0)$ \\
\hline & 3 & 12.2 & $1.71(d, 7.3)$ \\
\hline & $\mathrm{NH}$ & & $9.91(\mathrm{~s})$ \\
\hline \multirow[t]{5}{*}{ dehydrobutyrine-2 } & $C=O$ & ND & \\
\hline & 1 & ND & \\
\hline & 2 & 127.7 & $5.77(q, 7.0)$ \\
\hline & 3 & 12.9 & $1.93(d, 7.3)$ \\
\hline & $\mathrm{NH}$ & & $9.79(\mathrm{~s})$ \\
\hline \multirow[t]{7}{*}{ leucine } & $C=O$ & ND & \\
\hline & 1 & 51.2 & $4.24(\mathrm{~m})$ \\
\hline & 2 & 39.3 & $1.73(\mathrm{~m}), 1.52(\mathrm{~m})$ \\
\hline & 3 & 23.6 & $1.65(\mathrm{~m})$ \\
\hline & 4 & 20.6 & 0.81 \\
\hline & 5 & 22.6 & 0.86 \\
\hline & $\mathrm{NH}$ & & $8.13(d, 7.7)$ \\
\hline$p$-hydroxylphenylglycine & $C=0$ & ND & \\
\hline
\end{tabular}




\begin{tabular}{c|c|c|c}
1 & 56.6 & $5.42(\mathrm{~d}, 7.5)$ \\
2 & $\mathrm{ND}$ & \\
$3,3^{\prime}$ & 128.4 & $7.27(\mathrm{~d}, 9.0)$ \\
$4,4^{\prime}$ & 114.6 & $6.68(\mathrm{~d}, 8.6)$ \\
5 & $\mathrm{ND}$ & \\
$\mathrm{NH}$ & & $8.18(\mathrm{~d}, 7.7)$ \\
$\mathrm{C}=\mathrm{O}$ & $\mathrm{ND}$ & \\
1 & $\mathrm{ND}$ & \\
$2,2^{\prime}$ & 127.1 & $7.71(\mathrm{~d}, 8.8)$ \\
$3,3^{\prime}$ & 118.1 & $7.65(\mathrm{~d}, 8.8)$ \\
4 & $\mathrm{ND}$ & \\
$\mathrm{NH}$ & & $10.24(\mathrm{~s})$ \\
$\mathrm{C}=\mathrm{O}$ & $\mathrm{ND}$ & \\
1 & 56.7 & $3.95(\mathrm{~m})$ \\
2 & 65.3 & $3.95(\mathrm{~m})$ \\
3 & 18.4 & 0.91 \\
$\mathrm{NH}$ & & $7.61(\mathrm{~d}, 5.0)$
\end{tabular}


Table S10. NMR assignments for haereoplantin D in DMSO-d6 from $N$ - to $C$-terminus. The structure and numbering scheme for haereoplantin $D$ are shown above the table.

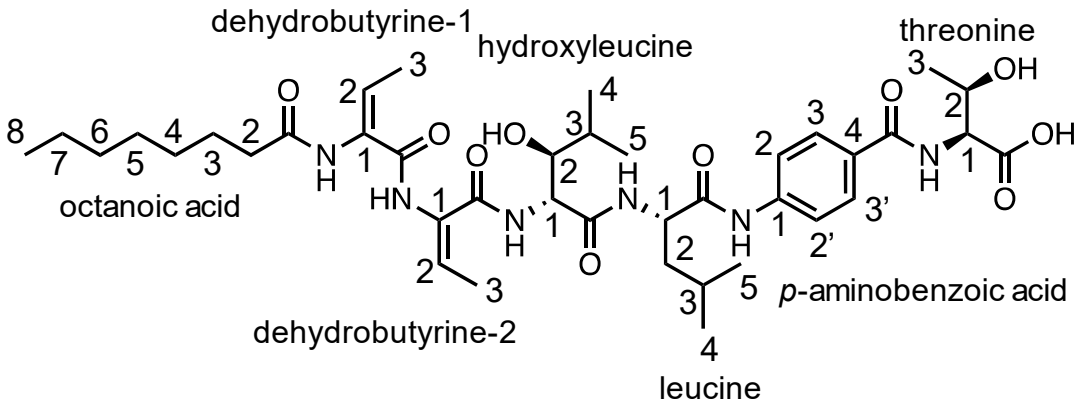

\begin{tabular}{|c|c|c|c|}
\hline Residue & Position & ${ }^{13} \mathrm{C}$ & ${ }^{1} \mathrm{H}$ (mult., $J$ in $\mathrm{Hz}$ ) \\
\hline \multirow[t]{4}{*}{ octanoic acid } & $C=O$ & ND & \\
\hline & 2 & 34.9 & $2.14(\mathrm{~m})$ \\
\hline & $3-7$ & $21.8-31.1$ & $1.12-1.50$ \\
\hline & 8 & 13.7 & 0.80 \\
\hline \multirow[t]{5}{*}{ dehydrobutyrine-1 } & $C=0$ & ND & \\
\hline & 1 & ND & \\
\hline & 2 & 119.1 & $5.60(q, 7.2)$ \\
\hline & 3 & 12.5 & $1.75(d, 7.3)$ \\
\hline & $\mathrm{NH}$ & & $10.10(\mathrm{~s})$ \\
\hline \multirow[t]{5}{*}{ dehydrobutyrine-2 } & $C=O$ & ND & \\
\hline & 1 & ND & \\
\hline & 2 & 125.5 & $5.75(q, 7.4)$ \\
\hline & 3 & 12.9 & $1.90(d, 7.3)$ \\
\hline & $\mathrm{NH}$ & & $9.96(\mathrm{~s})$ \\
\hline \multirow[t]{8}{*}{ hydroxyleucine } & $C=O$ & ND & \\
\hline & 1 & 55.8 & $4.43(\mathrm{~m})$ \\
\hline & 2 & 76.1 & $3.62(\mathrm{~m})$ \\
\hline & 3 & 30.3 & $1.63(\mathrm{~m})$ \\
\hline & 4 & 18.8 & 0.95 \\
\hline & 5 & 18.7 & 0.80 \\
\hline & $\mathrm{OH}$ & & $5.04(d, 7.5)$ \\
\hline & $\mathrm{NH}$ & & $7.87(d, 8.7)$ \\
\hline
\end{tabular}




\begin{tabular}{|c|c|c|c|}
\hline \multirow[t]{7}{*}{ leucine } & $C=0$ & ND & \\
\hline & 1 & 52.2 & $4.35(\mathrm{~m})$ \\
\hline & 2 & ND & $1.58(\mathrm{~m})$ \\
\hline & 3 & 23.7 & $1.66(\mathrm{~m})$ \\
\hline & 4 & 20.9 & 0.83 \\
\hline & 5 & 22.9 & 0.86 \\
\hline & $\mathrm{NH}$ & & $8.01(d, 7.9)$ \\
\hline \multirow[t]{6}{*}{$p$-aminobenzoic acid } & $\mathrm{C}=\mathrm{O}$ & ND & \\
\hline & 1 & ND & \\
\hline & $2,2^{\prime}$ & 118.4 & $7.66(d, 9.0)$ \\
\hline & $3,3^{\prime}$ & 127.1 & $7.71(d, 9.1)$ \\
\hline & 4 & ND & \\
\hline & $\mathrm{NH}$ & & 9.55 (s) \\
\hline \multirow[t]{5}{*}{ threonine } & $\mathrm{C}=\mathrm{O}$ & ND & \\
\hline & 1 & 56.9 & 3.95 (m) \\
\hline & 2 & 65.4 & $3.95(\mathrm{~m})$ \\
\hline & 3 & 18.6 & 0.91 \\
\hline & $\mathrm{NH}$ & & $7.63(d, 5.2)$ \\
\hline
\end{tabular}


Table S11. NMR assignments for haereoplantin E in DMSO- $d 6$ from $N$ - to $C$-terminus. The structure and numbering scheme for haereoplantin $\mathrm{E}$ are shown above the table.

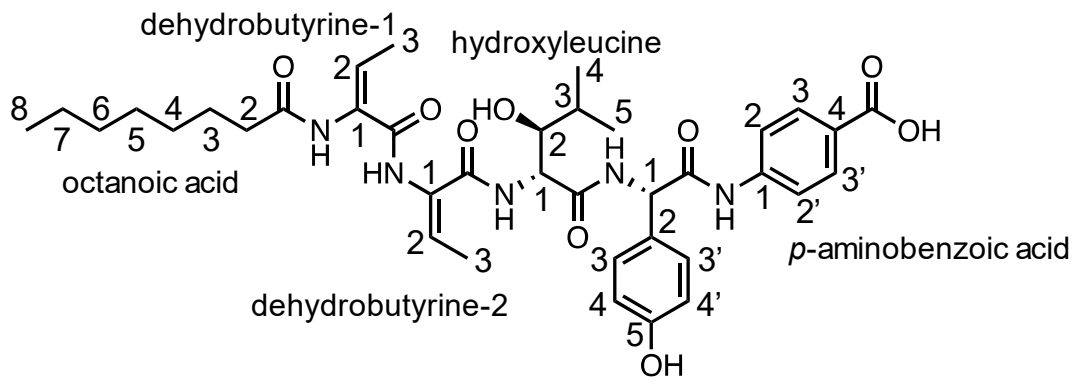

p-hydroxylphenylglycine

\begin{tabular}{|c|c|c|c|}
\hline Residue & Position & ${ }^{13} \mathrm{C}$ & ${ }^{1} \mathrm{H}$ (mult., $J$ in $\mathrm{Hz}$ ) \\
\hline \multirow[t]{4}{*}{ octanoic acid } & $C=O$ & ND & \\
\hline & 2 & 34.5 & $2.19(\mathrm{~m})$ \\
\hline & $3-7$ & 20.6-31.5 & $1.15-1.54$ \\
\hline & 8 & 13.5 & 0.81 \\
\hline \multirow[t]{5}{*}{ dehydrobutyrine-1 } & $C=0$ & ND & \\
\hline & 1 & ND & \\
\hline & 2 & 118.5 & $5.57(q, 7.4)$ \\
\hline & 3 & 12.3 & $1.72(d, 72)$ \\
\hline & $\mathrm{NH}$ & & $10.04(\mathrm{~s})$ \\
\hline \multirow[t]{5}{*}{ dehydrobutyrine-2 } & $C=0$ & ND & \\
\hline & 1 & ND & \\
\hline & 2 & 127.3 & $5.79(q, 7.4)$ \\
\hline & 3 & 13.0 & $1.92(d, 7.5)$ \\
\hline & $\mathrm{NH}$ & & $9.78(\mathrm{~s})$ \\
\hline \multirow[t]{8}{*}{ hydroxyleucine } & $C=O$ & ND & \\
\hline & 1 & 55.5 & $4.50(d d, 3.5,8.9)$ \\
\hline & 2 & 76.0 & $3.57(\mathrm{~m})$ \\
\hline & 3 & 29.8 & $1.63(\mathrm{~m})$ \\
\hline & 4 & 18.7 & 0.78 \\
\hline & 5 & 18.5 & 1.75 \\
\hline & $\mathrm{OH}$ & & $4.76(d, 8.5)$ \\
\hline & $\mathrm{NH}$ & & $7.88(d, 8.8)$ \\
\hline
\end{tabular}




\begin{tabular}{c|c|c|c}
$p$-hydroxylphenylglycine & $\mathrm{C}=\mathrm{O}$ & $\mathrm{ND}$ & \\
1 & 56.6 & $5.46(\mathrm{~d}, 8.0)$ \\
2 & $\mathrm{ND}$ & \\
$3,3^{\prime}$ & 128.3 & $7.25(\mathrm{~d}, 8.7)$ \\
$4,4^{\prime}$ & 114.5 & $6.67(\mathrm{~d}, 8.6)$ \\
5 & $\mathrm{ND}$ & \\
$\mathrm{NH}$ & & \\
$\mathrm{C}=\mathrm{O}$ & $\mathrm{ND}$ & \\
1 & $\mathrm{ND}$ & \\
$2,2^{\prime}$ & 129.2 & $7.75(\mathrm{~d}, 8.4)$ \\
$3,3^{\prime}$ & 117.5 & $7.46(\mathrm{~d}, 8.3)$ \\
4 & $\mathrm{ND}$ & $9.92(\mathrm{~s})$
\end{tabular}


Table S12. NMR assignments for burrioplantin A in DMSO-d6 from $N$ - to $C$-terminus. The structure and numbering scheme for burrioplantin $A$ are shown above the table.

p-hydroxylphenylglycine

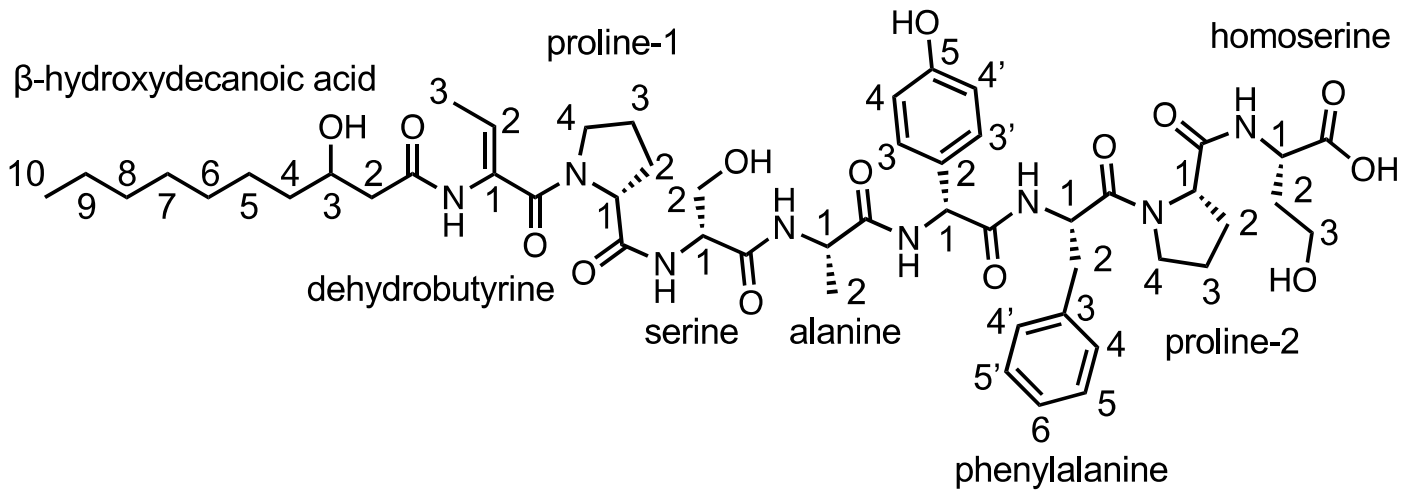

\begin{tabular}{|c|c|c|c|}
\hline Residue & Position & ${ }^{13} \mathrm{C}$ & ${ }^{1} \mathrm{H}$ (mult., $J$ in $\mathrm{Hz}$ ) \\
\hline \multirow[t]{5}{*}{$\beta$-hydroxydecanoic acid } & $C=0$ & 171.6 & \\
\hline & 2 & 42.8 & $2.30(\mathrm{~m})$ \\
\hline & 3 & 67.1 & $3.78(\mathrm{~m})$ \\
\hline & $4-9$ & $21.9-37.0$ & $1.19-1.40$ \\
\hline & 10 & 13.7 & $0.86(t, 6.5)$ \\
\hline \multirow[t]{5}{*}{ dehydrobutyrine } & $C=O$ & 166.97 & \\
\hline & 1 & 131.9 & \\
\hline & 2 & 119.2 & $5.55(q, 7.1)$ \\
\hline & 3 & 11.8 & $1.68(d, 6.6)$ \\
\hline & $\mathrm{NH}$ & & $9.76(\mathrm{~s})$ \\
\hline \multirow[t]{5}{*}{ proline-1 } & $C=O$ & 171.4 & \\
\hline & 1 & 60.2 & 4.25 \\
\hline & 2 & 29.1 & $2.14,1.77$ \\
\hline & 3 & 24.3 & $1.82,1.75$ \\
\hline & 4 & 48.8 & $3.60,3.45$ \\
\hline \multirow[t]{5}{*}{ serine } & $C=O$ & 169.6 & \\
\hline & 1 & 55.8 & 4.18 \\
\hline & 2 & 61.3 & 3.64 \\
\hline & $\mathrm{OH}$ & & 4.84 \\
\hline & $\mathrm{NH}$ & & $7.80(d, 7.7)$ \\
\hline
\end{tabular}




\begin{tabular}{|c|c|c|c|}
\hline \multirow[t]{4}{*}{ alanine } & $C=0$ & 171.5 & \\
\hline & 1 & 48.5 & 4.20 \\
\hline & 2 & 17.5 & $1.18(\mathrm{~d}, 7.0)$ \\
\hline & $\mathrm{NH}$ & & $7.59(d, 6.2)$ \\
\hline \multirow[t]{7}{*}{$p$-hydroxylphenylglycine } & $C=O$ & 169.9 & \\
\hline & 1 & 54.4 & $5.40(d, 8.5)$ \\
\hline & 2 & 129.1 & $6.51(d, 7.9)$ \\
\hline & $3,3^{\prime}$ & 114.3 & $6.84(d, 7.9)$ \\
\hline & $4,4^{\prime}$ & 127.1 & \\
\hline & 5 & 156.3 & \\
\hline & $\mathrm{NH}$ & & $8.08(d, 8.3)$ \\
\hline \multirow[t]{6}{*}{ phenylalanine } & $C=O$ & 170.1 & \\
\hline & 1 & 52.8 & 4.53 \\
\hline & 2 & 36.5 & $2.98,2.75$ \\
\hline & 3 & 137.6 & \\
\hline & $4,4^{\prime}, 5,5^{\prime}, 6$ & 125.9-129.0 & $7.12-7.20$ \\
\hline & $\mathrm{NH}$ & & $8.82(d, 7.7)$ \\
\hline \multirow[t]{5}{*}{ proline-2 } & $C=0$ & 172.5 & \\
\hline & 1 & 59.3 & 4.48 \\
\hline & 2 & 28.4 & $1.93,1.99$ \\
\hline & 3 & 24.3 & 1.90 \\
\hline & 4 & 46.5 & 3.63 \\
\hline \multirow[t]{5}{*}{ homoserine } & $C=O$ & 173.1 & \\
\hline & 1 & 48.8 & 4.31 \\
\hline & 2 & 33.8 & $1.70,1.81$ \\
\hline & 3 & 56.8 & $3.39,3.44$ \\
\hline & $\mathrm{NH}$ & & $8.13(d, 7.2)$ \\
\hline
\end{tabular}


Table S13. Predicted functions for proteins in the hpt gene cluster.

\begin{tabular}{ccc}
\hline Protein & Putative function & NCBl accession \\
\hline HptA & VOC family protein & WP_082465193.1 \\
HptB & Aminodeoxychorismate synthase & WP_055138301.1 \\
HptC & NRPS (C-A-T-C-A-T-C-A-T-C-A-T-C-A-T-TE) & WP_055138302.1 \\
HptD & Cupin-like domain containing protein & WP_158512003.1 \\
HptE & MFS efflux pump & WP_042624381.1 \\
HptF & ABC transporter permease & WP_042624382.1 \\
HptG & ABC transporter permease & WP_042624383.1 \\
HptH & ABC transporter substrate binding protein & WP_055138304.1 \\
\hline
\end{tabular}


Table S14. Predicted functions for proteins in the bpt gene cluster.

\begin{tabular}{|c|c|c|}
\hline Protein & Putative function & NCBI accession \\
\hline BptA & four helix bundle domain-containing protein & WP_055140513.1 \\
\hline BptB & Glycosyltransferase & WP_055140514.1 \\
\hline BptC & Thioredoxin family protein & WP_055140515.1 \\
\hline BptD & DUF1223 domain containing protein & WP_055140516.1 \\
\hline BptE & $\begin{array}{c}\text { NRPS (C-A-T-C-A-T-C-A-T-C-A-T- } \\
\text { C-A-T-C-A-T-C-A-T-TE) }\end{array}$ & WP_055140517.1 \\
\hline BptF & Porin & WP_042628186.1 \\
\hline BptG & methyl-accepting chemotaxis protein & WP_055140518.1 \\
\hline BptH & Hypothetical & WP_055140519.1 \\
\hline Bptl & MFS transporter & WP_055140520.1 \\
\hline BptJ & phytanoyl-CoA dioxygenase family protein & WP_055140521.1 \\
\hline BptK & 5-enolpyruvylshikimate-3-phosphate synthase & WP_042628191.1 \\
\hline
\end{tabular}


Table S15. NMR assignments for gladiobactin in DMSO-d6 from $N$ - to $C$-terminus. The structure and number scheme for the compound is shown above the table.

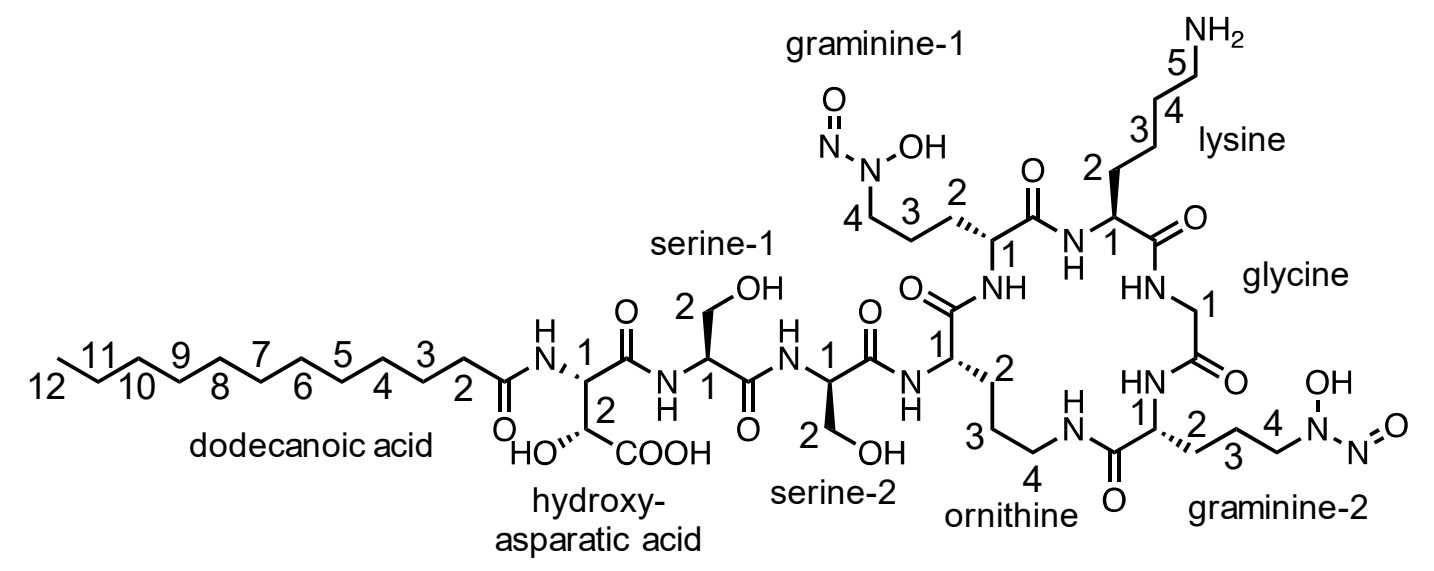

\begin{tabular}{|c|c|c|c|}
\hline Residue & Position & ${ }^{13} \mathrm{C}$ & ${ }^{1} \mathrm{H}$ (mult., $J$ in $\mathrm{Hz}$ ) \\
\hline \multirow[t]{4}{*}{ dodecanoic acid } & $C=0$ & 171.3 & \\
\hline & 2 & 34.9 & $2.06(\mathrm{~m})$ \\
\hline & $3-11$ & $21.0-32.1$ & $1.09-1.48$ \\
\hline & 12 & 13.8 & $0.85(t, 7.1)$ \\
\hline \multirow[t]{5}{*}{ hydroxyasparatic acid } & $C=O$ & 171.1 & \\
\hline & 1 & 57.1 & $3.77(d d, 5.4,10.2)$ \\
\hline & 2 & 73.0 & $3.73(\mathrm{~m})$ \\
\hline & $\mathrm{COOH}$ & 177.6 & \\
\hline & $\mathrm{NH}$ & & $7.62(d, 5.2)$ \\
\hline \multirow[t]{5}{*}{ serine-1 } & $C=0$ & 171.6 & \\
\hline & 1 & 55.5 & $3.90(\mathrm{~m})$ \\
\hline & 2 & 61.1 & $3.66,3.73(\mathrm{~m})$ \\
\hline & $\mathrm{OH}$ & & 4.99 \\
\hline & $\mathrm{NH}$ & & $6.82(d, 6.7)$ \\
\hline \multirow[t]{4}{*}{ serine-2 } & $C=O$ & 169.6 & \\
\hline & 1 & 56.9 & $3.93(\mathrm{~m})$ \\
\hline & 2 & 59.4 & $3.60,4.07(\mathrm{~m})$ \\
\hline & $\mathrm{NH}$ & & $8.94(d, 5.6)$ \\
\hline \multirow[t]{2}{*}{ ornithine } & $C=0$ & 170.7 & \\
\hline & 1 & 55.1 & $3.54(\mathrm{~m})$ \\
\hline
\end{tabular}




\begin{tabular}{|c|c|c|c|}
\hline & 2 & 26.9 & $1.35,1.44(\mathrm{~m})$ \\
\hline & 3 & 24.3 & $1.17(\mathrm{~m})$ \\
\hline & 4 & 36.2 & $2.66,3.46(\mathrm{~m})$ \\
\hline & $\mathrm{NH}$ & & $6.14(d, 10)$ \\
\hline & $\mathrm{NH}$ & & $6.72(d, 4.3)$ \\
\hline graminine-1 & $C=0$ & 172.2 & \\
\hline & 1 & 50.7 & $4.24(\mathrm{~m})$ \\
\hline & 2 & 27.5 & $1.15,1.41(\mathrm{~m})$ \\
\hline & 3 & 22.5 & $1.59,1.83(\mathrm{~m})$ \\
\hline & 4 & 55.9 & $4.13(\mathrm{~m})$ \\
\hline & $\mathrm{NH}$ & & $6.75(d, 7.9)$ \\
\hline lysine & $C=O$ & 173.5 & \\
\hline & 1 & 54.6 & $3.69(\mathrm{~m})$ \\
\hline & 2 & 29.9 & $1.57,1.63(\mathrm{~m})$ \\
\hline & 3 & 21.8 & $1.28,1.41(\mathrm{~m})$ \\
\hline & 4 & 27.7 & $1.52(\mathrm{~m})$ \\
\hline & 5 & 38.3 & $2.71(\mathrm{~m})$ \\
\hline & $\mathrm{NH}$ & & $8.54(\mathrm{~s})$ \\
\hline glycine & $\mathrm{C}=\mathrm{O}$ & 172.5 & \\
\hline & 1 & 42.4 & $3.48,3.72(\mathrm{~m})$ \\
\hline & $\mathrm{NH}$ & & $8.85(\mathrm{~m})$ \\
\hline graminine-2 & $\mathrm{C}=\mathrm{O}$ & 168.8 & \\
\hline & 1 & 54.1 & $4.00(\mathrm{~m})$ \\
\hline & 2 & 27.6 & $1.55,2.25(\mathrm{~m})$ \\
\hline & 3 & 21.7 & $1.82,2.00(\mathrm{~m})$ \\
\hline & 4 & 57.9 & $4.02,4.58(\mathrm{~m})$ \\
\hline & $\mathrm{NH}$ & & $7.58(d, 8)$ \\
\hline
\end{tabular}


Table S16. Predicted functions for proteins in the gld gene cluster.

\begin{tabular}{|c|c|c|}
\hline Protein & Putative function & NCBI accession \\
\hline GldA & MbtH family protein & WP_013690465.1 \\
\hline GldB & Thioesterase & WP_036056054.1 \\
\hline GldC & TauD family dioxygenase & WP_036056055.1 \\
\hline GldD & NRPS (C-A-T-E-C-A-T-C-A-T) & WP_036056057.1 \\
\hline GldE & NRPS (C-A-T-E-TE) & WP_052710563.1 \\
\hline GldF & $\mathrm{ABC}$ transporter, ATP-binding & WP_017922115.1 \\
\hline GldG & $\mathrm{ABC}$ transporter, iron-compound binding & WP_036056058.1 \\
\hline GldH & $A B C$ transporter permease & WP_036056059.1 \\
\hline Gldl & TonB-dependent siderophore receptor & WP_036056060.1 \\
\hline GldJ & Peptide synthetase, GrbD homolog & WP_036056061.1 \\
\hline GldK & Yqcl/YcgG protein, GrbE homolog & WP_036029368.1 \\
\hline GldL & NRPS (FAL-T-C-A-T-C-A-T) & WP_036056063.1 \\
\hline GldM & NRPS (C-A-T-E-C-A-T) & WP_036056065.1 \\
\hline GldN & $\mathrm{ABC}$ transporter & WP_036056067.1 \\
\hline
\end{tabular}




\section{SI Figures}

Figure S1. All 72 differential self-organizing maps from HPLC-MS analysis of 72 B. plantarii Tn mutants. Red and yellow colored nodes in each of the difference maps contain features that are $>3$-fold more abundant than the wild-type average.

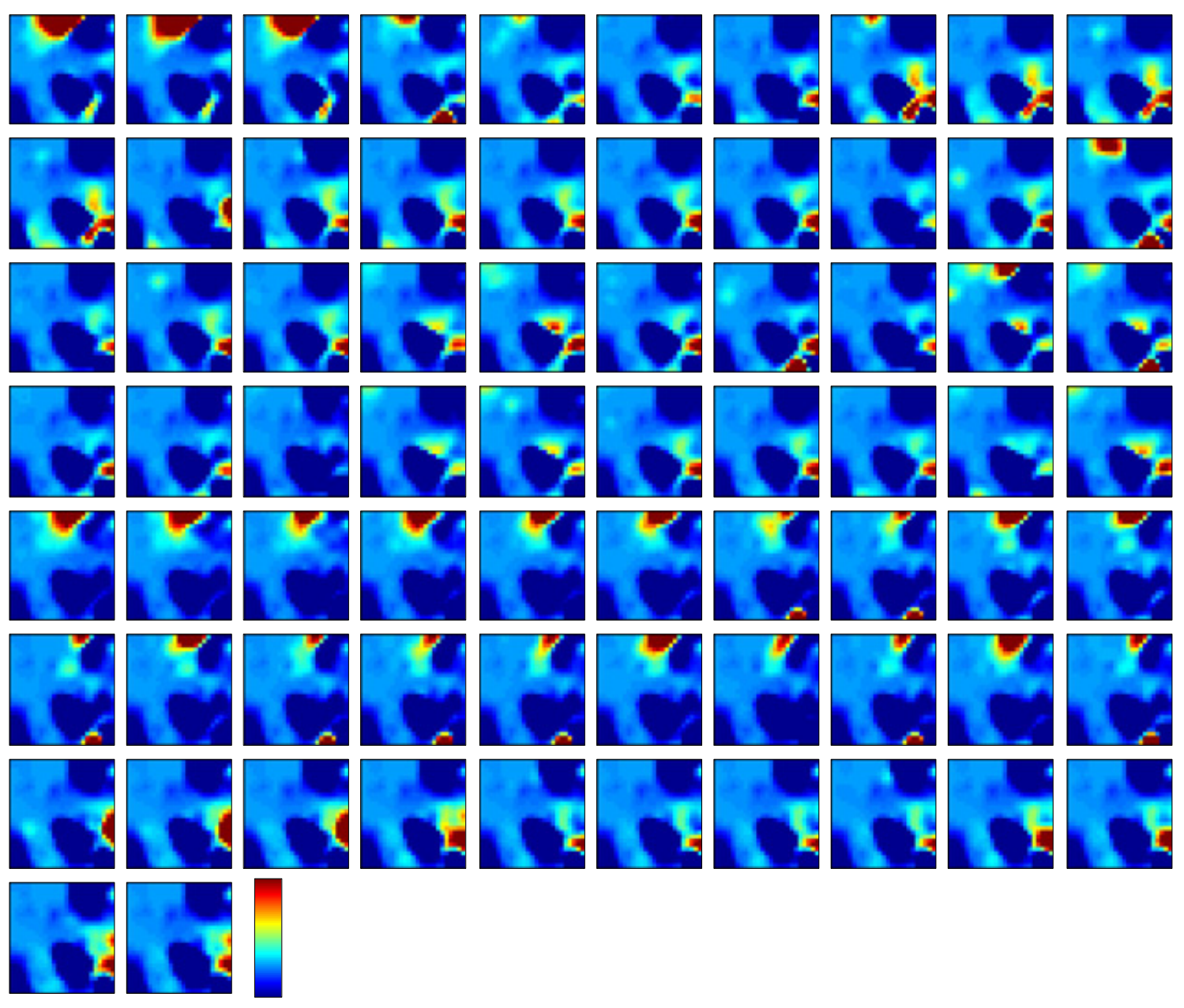


Figure S2. $800 \mathrm{MHz} N \mathrm{NMR}$ spectra of haereoplantin $\mathrm{A}$ in DMSO-d6. Shown are ${ }^{1} \mathrm{H},{ }^{13} \mathrm{C}, \mathrm{COSY}$, HSQC, HMBC, and NOESY spectra.

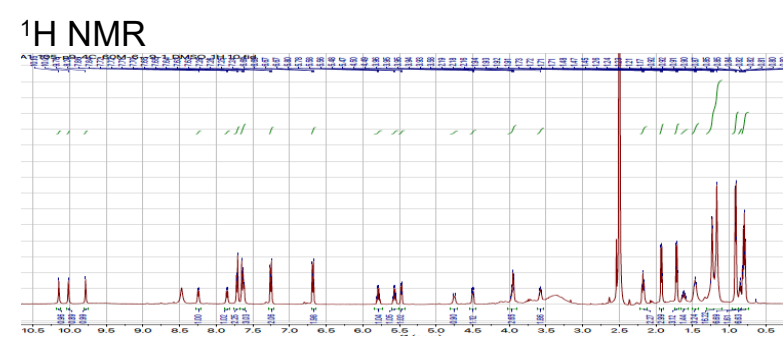

$\delta / p p m$
${ }^{13} \mathrm{C}$ NMR

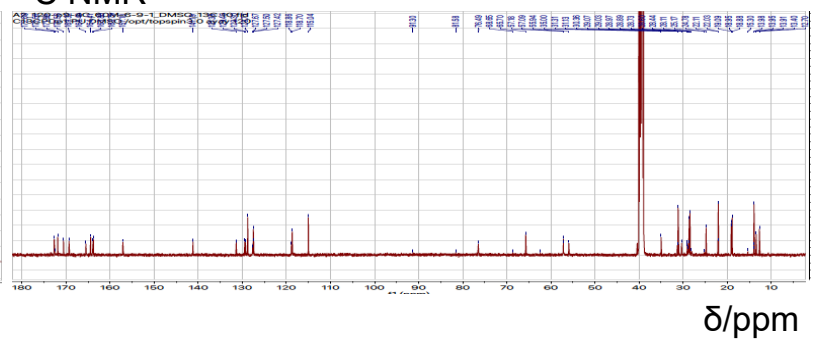

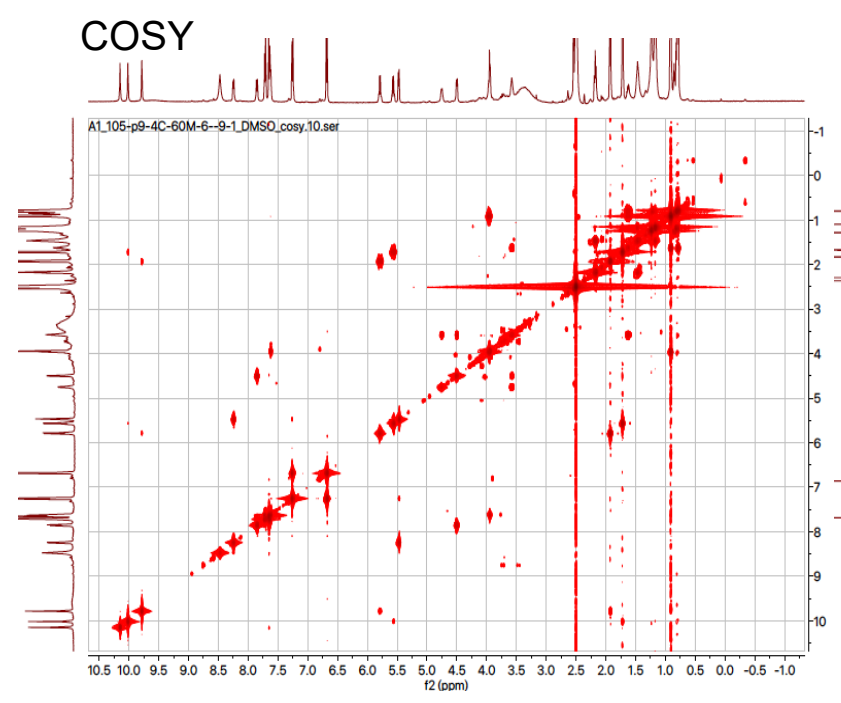
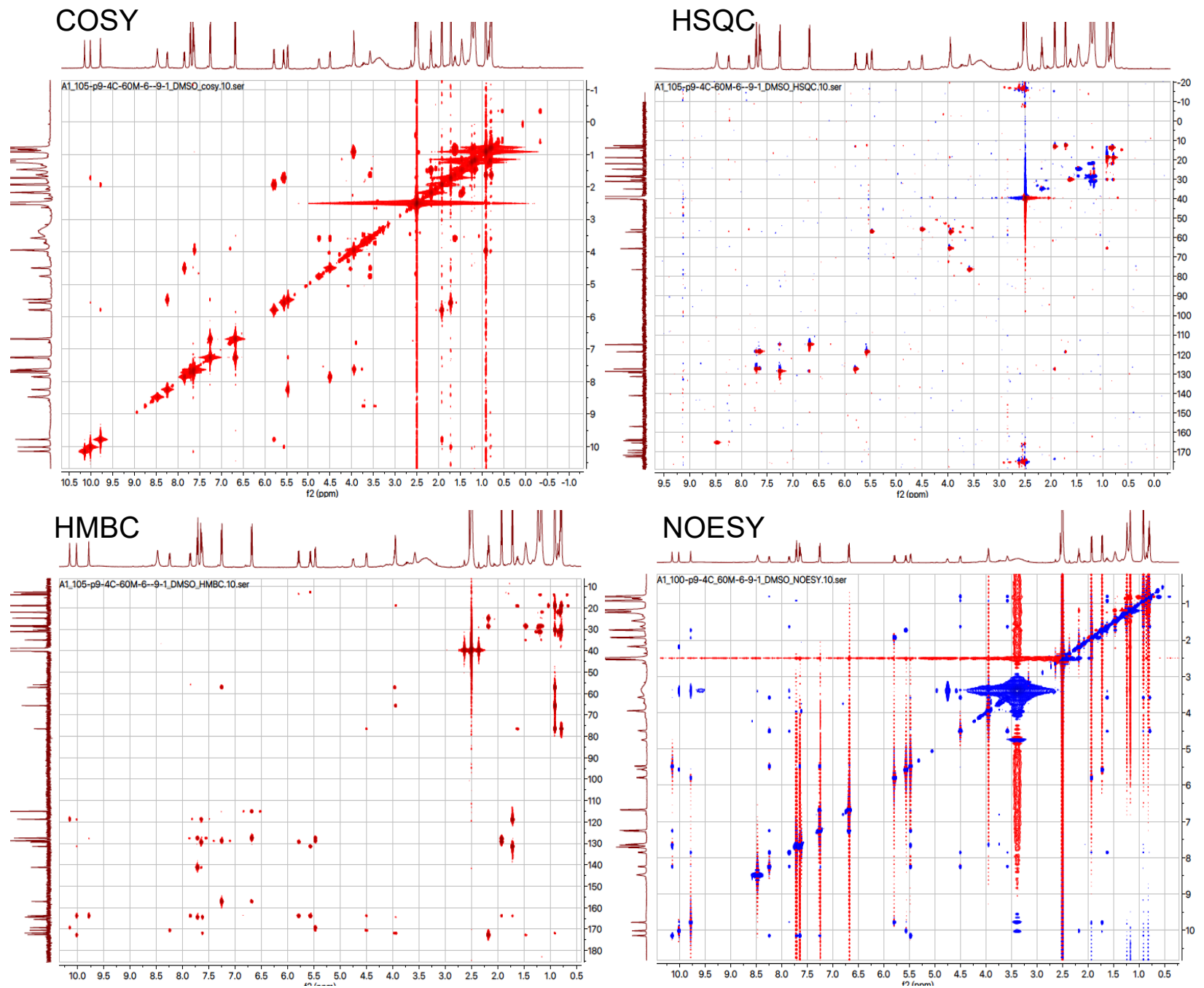
Figure S3. $800 \mathrm{MHz}$ NMR spectra of burrioplantin A in DMSO-d6. Shown are ${ }^{1} \mathrm{H},{ }^{13} \mathrm{C}, \mathrm{COSY}$, TOCSY (page S31) and HSQC, HMBC, and ROESY spectra (page S32).

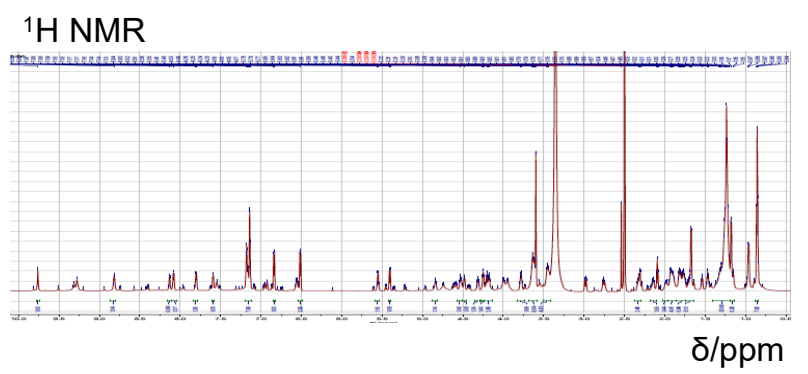

${ }^{13} \mathrm{C}$ NMR
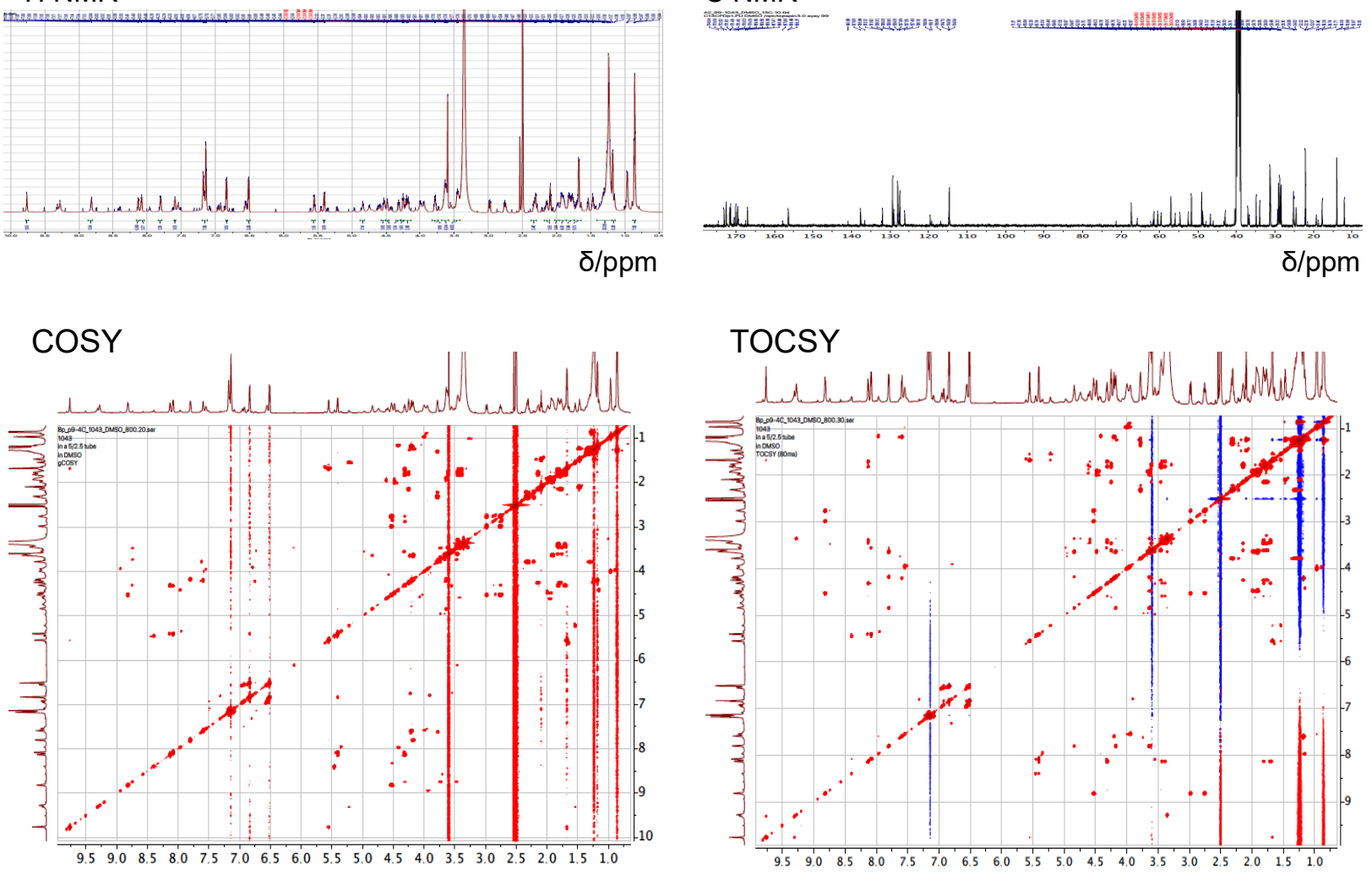


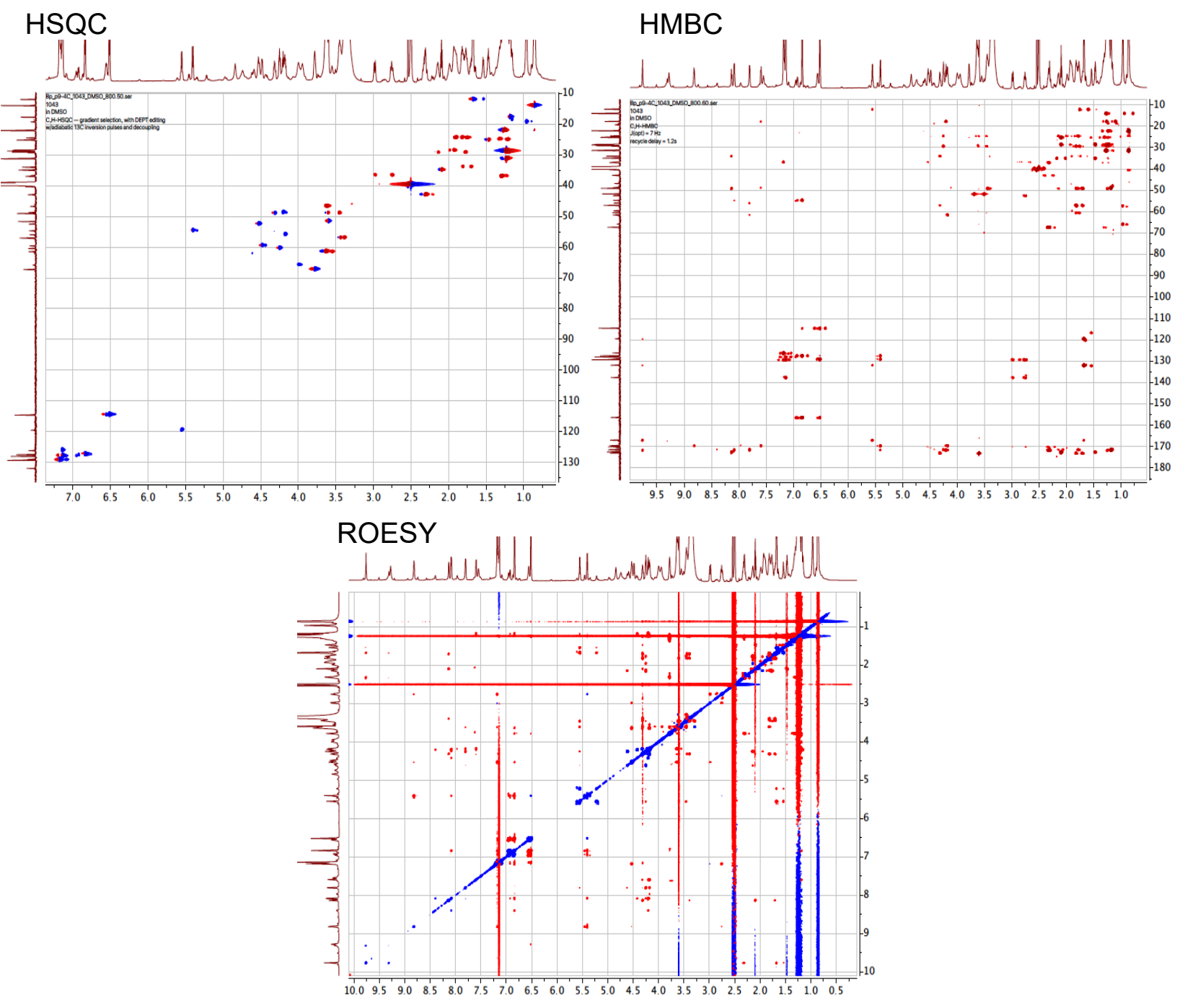


Figure S4. Proposed biosynthetic pathway for haereoplantin A (top) and burrioplantin A (bottom). See Tables S13-S14.
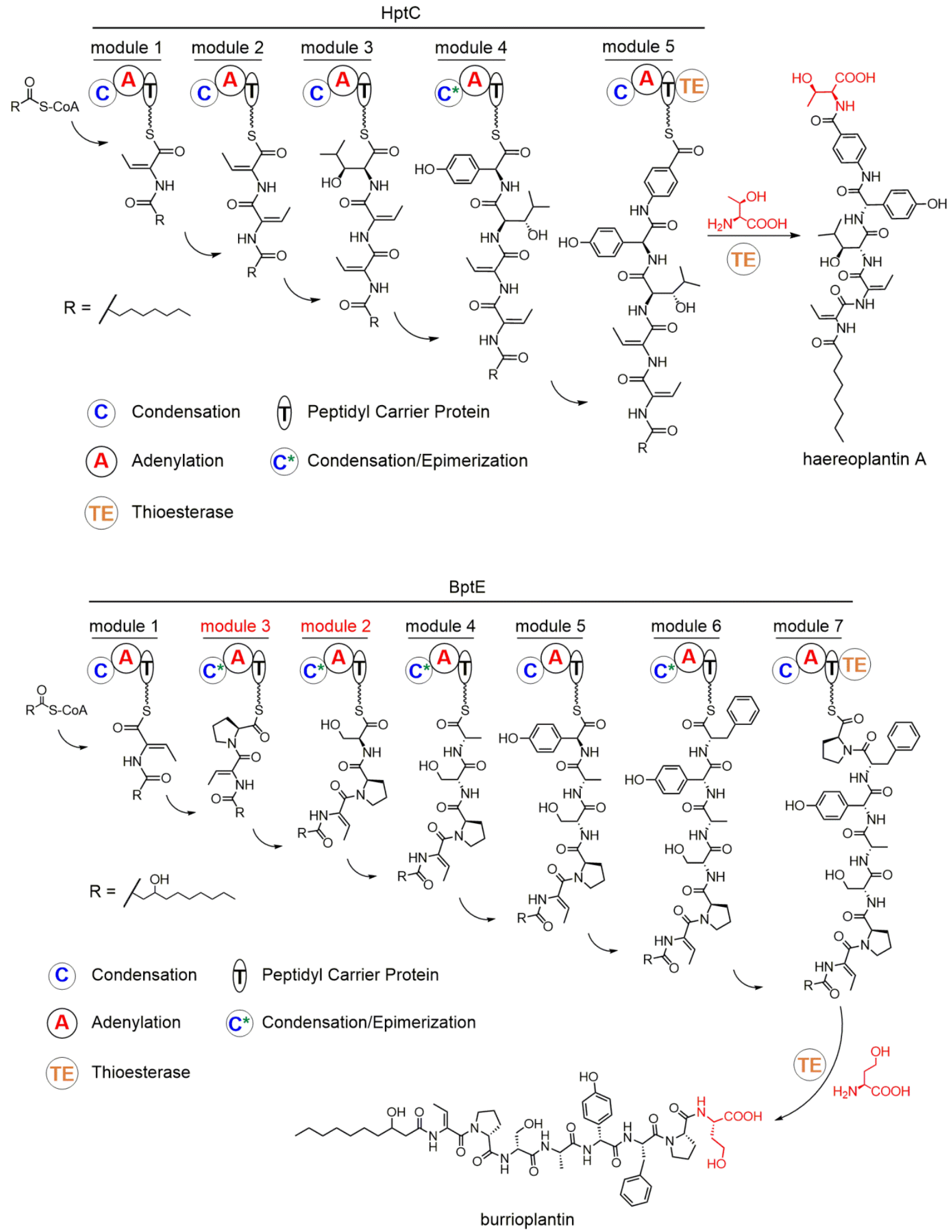
Figure S5. $800 \mathrm{MHz}$ NMR spectra of gladiobactin in DMSO-d6. Shown ${ }^{1} \mathrm{H},{ }^{13} \mathrm{C}$, COSY, HSQC, TOCSY, and HMBC spectra.
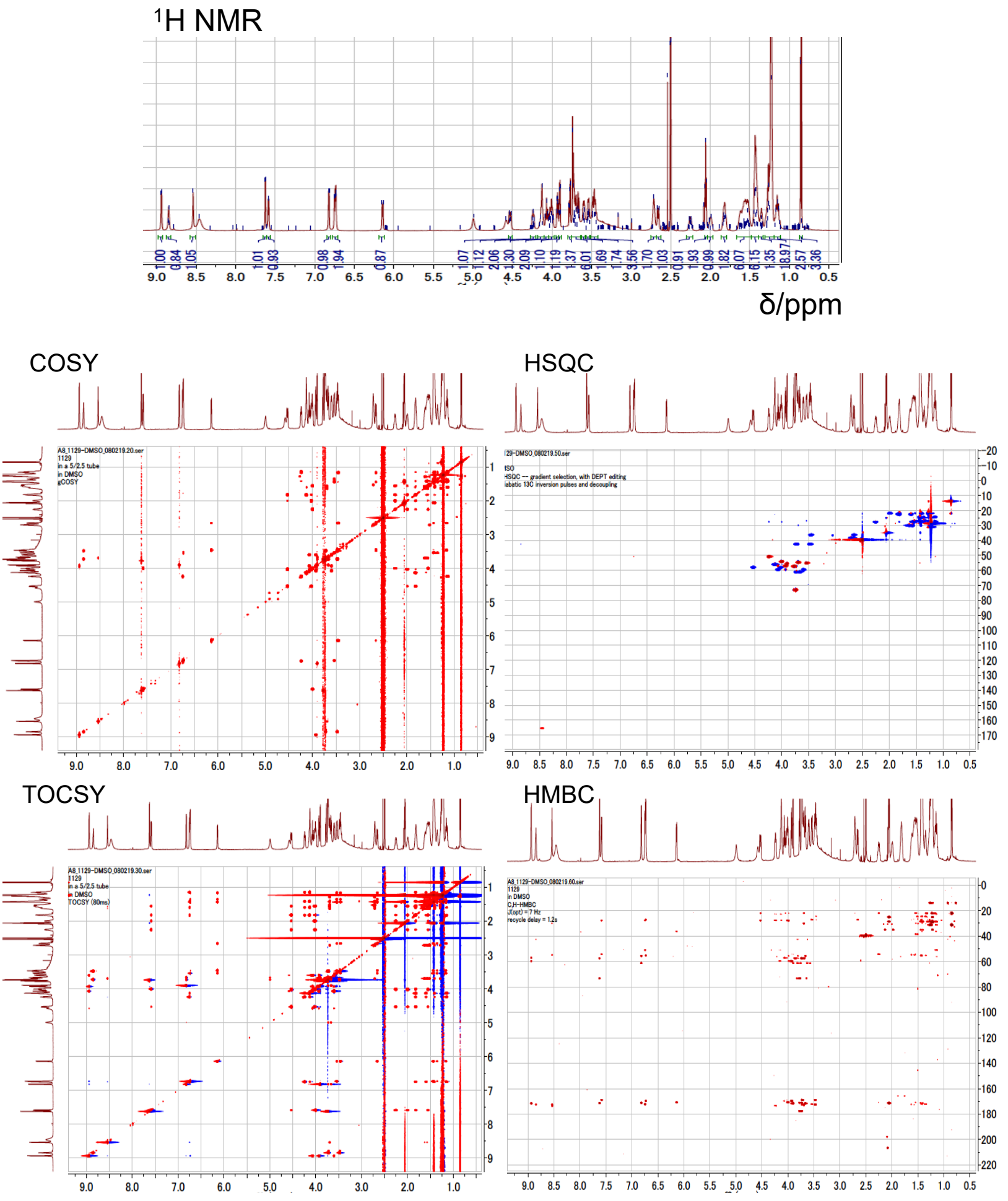
Figure S6. HR-MS/MS analysis of ferric-gladiobactin A. The loss of NO fragments is indicated.

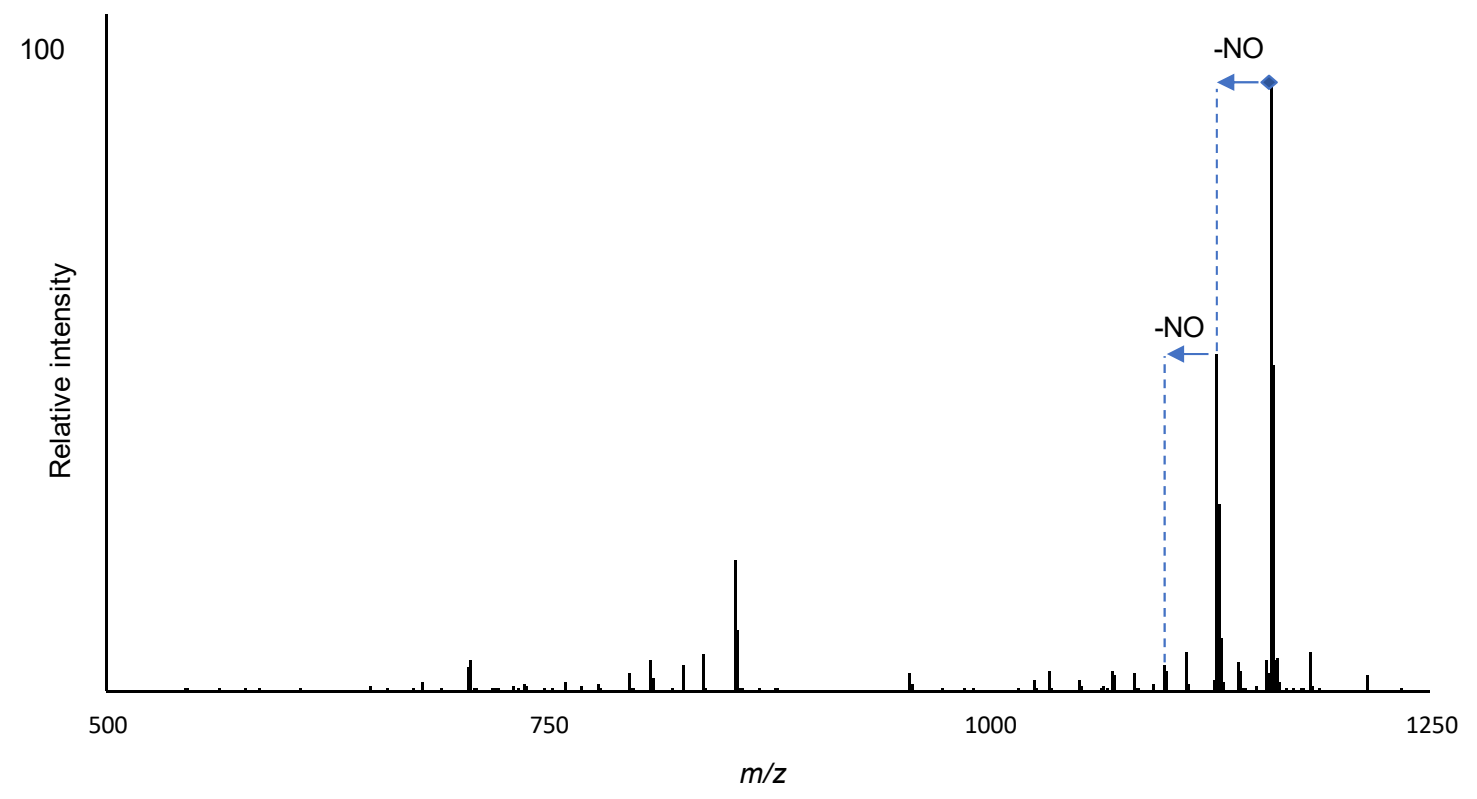


Figure S7. Proposed biosynthetic pathway for gladiobactin A. See Table S16.

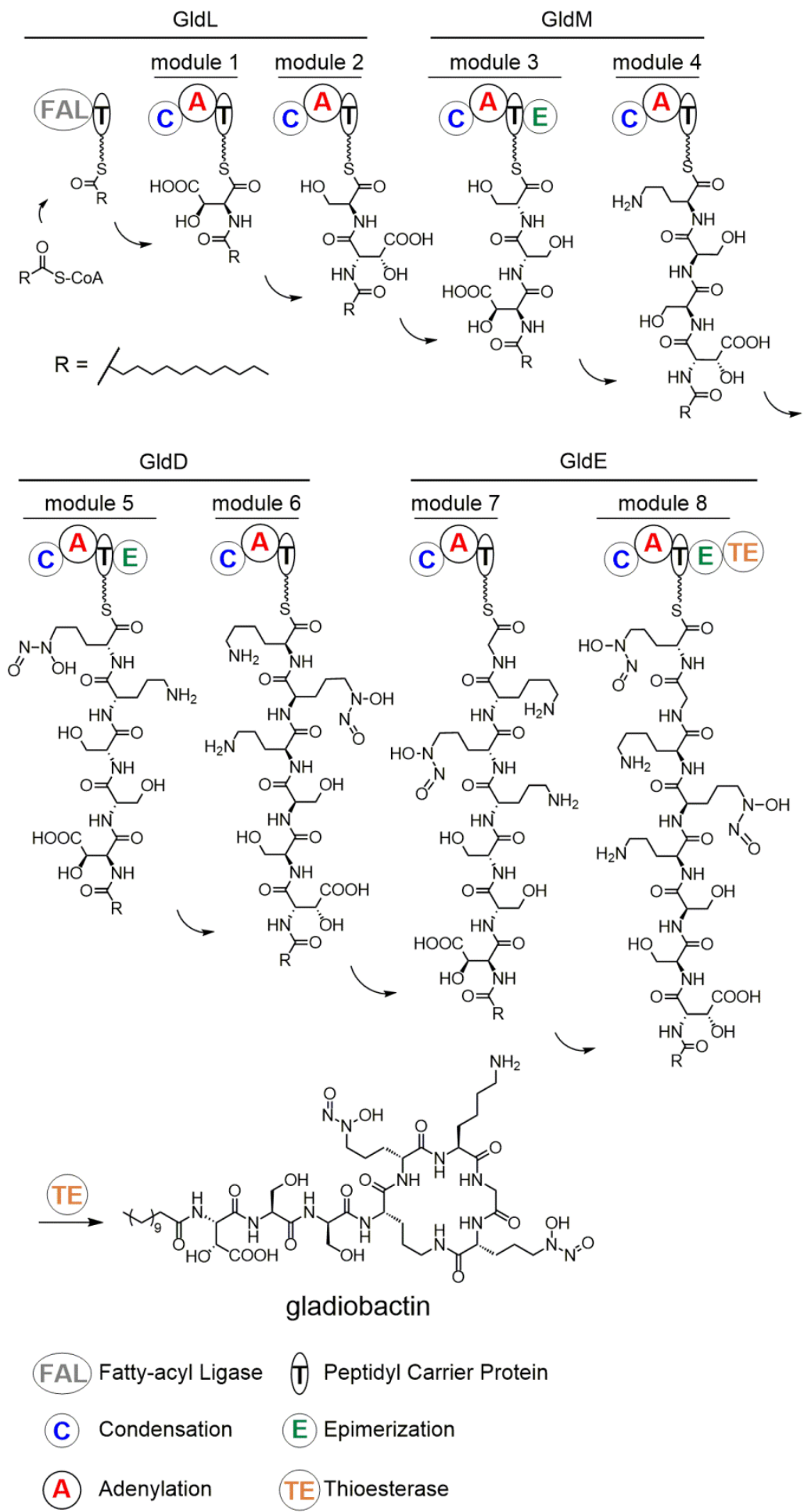




\section{$\underline{\text { SI References }}$}

1) Goryshin, I. Y., Jendrisak, J., Hoffman, L. M., Meis, R., and Reznikoff, W. S. (2000) Insertional transposon mutagenesis by electroporation of released Tn5 transposition complexes. Nat. Biotechnol. 18, 97-100.

2) Goodwin, C. R., Covington, B. C., Derewacz, D. K., McNees, C. R., Wikswo, J. P., McLean, J. A., and Bachmann, B. O. (2015) Structuring microbial metabolic responses to multiplexed stimuli via self-organizing metabolomics maps. Chem. Biol. 22, 661-670.

3) Xu, F., Wu, Y., Zhang, C., Davis, K. M., Moon, K., Bushin, L. B., and Seyedsayamdost, M. R. (2019) A genetics-free method for high-throughput discovery of cryptic microbial metabolites. Nat. Chem. Biol. 15, 161-168.

4) Marfey, P. (1984) Determination of D-amino acids. II. Use of a bifunctional reagent, 1,5-difluoro-2,4-dinitrobenzene. Carlsberg Res. Commun. 49, 591-596.

5) Wang, R., Gallant, É., and Seyedsayamdost, M. R. (2016) Investigation of the genetics and biochemistry of roseobacticide production in the Roseobacter clade bacterium Phaeobacter inhibens. MBio 7, e02118-15. 